OPEN ACCESS

Edited by:

Laurent Deluc,

Oregon State University,

United States

Reviewed by:

Maria F. Drincovich,

Center for Photosynthetic and Biochemical Studies (CEFOBI) Rosario National University, Argentina

George A. Manganaris,

Cyprus University of Technology,

Cyprus

${ }^{*}$ Correspondence: Livio Trainott

livio.trainotti@unipd.it

Specialty section:

This article was submitted to Crop Science and Horticulture,

a section of the journal

Frontiers in Plant Science

Received: 30 June 2017 Accepted: 19 September 2017 Published: 11 October 2017

Citation:

Busatto N, Salvagnin U, Resentini $F$ Quaresimin S, Navazio L, Marin O, Pellegrini M, Costa F, Mierke DF and

Trainotti L (2017) The Peach RGF/GLV Signaling Peptide pCTG134 Is Involved in a Regulatory Circuit That Sustains Auxin and Ethylene Actions.

Front. Plant Sci. 8:1711. doi: 10.3389/fpls.2017.01711

\section{The Peach RGF/GLV Signaling Peptide pCTG134 Is Involved in a Regulatory Circuit That Sustains Auxin and Ethylene Actions}

\author{
Nicola Busatto ${ }^{1,2}$, Umberto Salvagnin ${ }^{1}$, Francesca Resentini', Silvia Quaresimin ${ }^{1}$, \\ Lorella Navazio', Oriano Marin ${ }^{3}$, Maria Pellegrini4, Fabrizio Costa ${ }^{2}$, Dale F. Mierke ${ }^{4}$ and \\ Livio Trainotti ${ }^{*}$ *

\begin{abstract}
${ }^{1}$ Department of Biology, University of Padova, Padova, Italy, ${ }^{2}$ Department of Genomics and Crop Biology, Research and Innovation Centre, Fondazione Edmund Mach, Trento, Italy, ${ }^{3}$ Department of Biomedical Sciences, University of Padova, Padova, Italy, ${ }^{4}$ Department of Chemistry, Dartmouth College, Hanover, NH, United States
\end{abstract}

In vascular plants the cell-to-cell interactions coordinating morphogenetic and physiological processes are mediated, among others, by the action of hormones, among which also short mobile peptides were recognized to have roles as signals. Such peptide hormones (PHs) are involved in defense responses, shoot and root growth, meristem homeostasis, organ abscission, nutrient signaling, hormone crosstalk and other developmental processes and act as both short and long distant ligands. In this work, the function of CTG134, a peach gene encoding a ROOT GROWTH FACTOR/GOLVEN-like PH expressed in mesocarp at the onset of ripening, was investigated for its role in mediating an auxin-ethylene crosstalk. In peach fruit, where an auxin-ethylene crosstalk mechanism is necessary to support climacteric ethylene synthesis, CTG134 expression peaked before that of ACS1 and was induced by auxin and 1-methylcyclopropene (1-MCP) treatments, whereas it was minimally affected by ethylene. In addition, the promoter of CTG134 fused with the GUS reporter highlighted activity in plant parts in which the auxin-ethylene interplay is known to occur. Arabidopsis and tobacco plants overexpressing CTG134 showed abnormal root hair growth, similar to wild-type plants treated with a synthetic form of the sulfated peptide. Moreover, in tobacco, lateral root emergence and capsule size were also affected. In Arabidopsis overexpressing lines, molecular surveys demonstrated an impaired hormonal crosstalk, resulting in a re-modulated expression of a set of genes involved in both ethylene and auxin synthesis, transport and perception. These data support the role of pCTG134 as a mediator in an auxin-ethylene regulatory circuit and open the possibility to exploit this class of ligands for the rational design of new and environmental friendly agrochemicals able to cope with a rapidly changing environment.

Keywords: Arabidopsis thaliana, CLE-LIKE (CLEL), fruit ripening, GOLVEN (GLV), Nicotiana tabacum, peptide hormone, Prunus persica, ROOT GROWTH FACTOR (RGF) 


\section{INTRODUCTION}

Plants are complex multicellular organisms requiring the coordination of a wide range of processes related to growth, reproduction and stress responses. For decades hormones, such as auxin, ethylene and abscisic acid have been considered as the primary chemical signals involved in the intracellular communications in higher plants. The action of these hormones depends not only on the cellular context, but also on the relationship established among them. To date, the hormonal crosstalk has been mainly investigated in Arabidopsis, which shed light, among others, on the crosstalk between auxin and ethylene (Van de Poel et al., 2015). The first, most evident and studied effect of their interaction is about the regulation of root morphogenesis. Indeed, in this organ it has been demonstrated that root hair formation, elongation (Pitts et al., 1998; Dolan, 2001) and differentiation, together with the development of lateral roots are regulated by the interplay occurring between auxin and ethylene (Zhang et al., 2016).

In addition to the traditional hormones, a plethora of secreted and non-secreted peptides have been recognized as regulators of various aspects of plant growth, including defense responses, callus growth, meristem organization, self-incompatibility and fertilization, organ abscission and shoot and root development [reviewed in (Matsubayashi, 2014; Tavormina et al., 2015)]. Moreover peptide hormones (PHs) can synergically interact with hormones establishing functional interplay. Cellular and genetic evidences have shown a physiological connection between hormones and PHs. For instance, ROOT GROWTH FACTOR/GOLVEN/CLE-Like (RGF/GLV/CLEL) peptides can alter auxin gradients by changing the turnover of IAA carriers (Whitford et al., 2012). In Arabidopsis the RGF/GLV/CLEL family codes for secretory peptides and includes 11 genes with similar structure (Matsuzaki et al., 2010; Whitford et al., 2012) and undergoing specific post-translation modifications by sulfation of a conserved Tyr residue and hydroxylation of a Pro residue. In Arabidopsis, RGF/GLV/CLEL mutants shown an impaired gravitropic response in root hypocotyl.

Despite the importance of this regulatory mechanism, the biology of $\mathrm{PHs}$ is still in its infancy, especially in nonmodel but agronomically relevant species. A putative $\mathrm{PH}$ in particular, namely CTG134 GLV-like, was identified in peach through a comprehensive transcriptomic survey (Tadiello et al., 2016). This gene resulted to be expressed at the transition between preclimacteric and climacteric stage in peach fruit. Moreover, while CTG134 was induced by exogenous treatment of 1-methylcyclopropene (1-MCP), an ethylene competitor largely used to delay the normal physiological ripening progression (Watkins, 2006), its expression was also totally repressed in ripe fruit of stony hard, a peach mutant showing impairment both in ethylene production and cell wall disassembly metabolism (Pan et al., 2015). Prunus persica is a fleshy climacteric fruit, whose ripening syndrome extensively relies on the presence of a burst in the production of the plant hormone ethylene accompanied by a respiratory increase occurring at the late stage of fruit ripening (Looney et al., 1974). The molecular mechanism underlying the transition of ethylene synthesis from auto-inhibitory system
1 (used for basal level of hormone synthesis) to autocatalytic system 2 (used for large production of the hormone) is still far from being fully understood, but the need of auxin is strongly supported (Miller et al., 1987; Trainotti et al., 2007; Tatsuki et al., 2013; Pan et al., 2015; Tadiello et al., 2016). In this work, the functional validation of pCTG134 was carried out in Arabidopsis and tobacco, providing new evidence about its role as a major regulator in the auxin/ethylene crosstalk. This and other functions of RGF/GLV/CLEL peptides suggest the possibility for the rational design of novel and environmental friendly agrochemicals with interesting potentials to control fruit quality and post-harvest life in a rapidly changing environment.

\section{MATERIALS AND METHODS}

\section{Plant Materials}

Peach fruits were collected from cv. 'Redhaven' (RH) and cv. "Stark Red Gold" (SRG) as described in Tadiello et al. (2016). RH peaches at different stages of development [i.e., S1, S2, S3I, S3II, S4I, and S4II, corresponding to $40,65,85,95,115$, and 120 days after full bloom (dAFB), respectively] were collected early in the morning and mesocarps were frozen in liquid nitrogen after removal of the peel and stored at $-80^{\circ} \mathrm{C}$ until used. Fruits for qRT-PCR analyses were the same used in Tadiello et al. (2016), while those used for the in situ hybridization were collected in 2015. The heterologous CTG134 overexpression was carried out in Arabidopsis and tobacco plants. Seeds of Arabidopsis thaliana Columbia accession (Col-0) were surface-sterilized, stratified overnight at $4^{\circ} \mathrm{C}$ and germinated on plant growth medium (Murashige and Skoog, 1962) or in potting soil at $22^{\circ} \mathrm{C}$. To characterize root growth, MS plates were tilted with an angle of $45^{\circ}$. Nicotiana tabacum $\mathrm{SNN}$ plants were instead grown following standard protocols in controlled greenhouse.

\section{Hormone Treatments on Redhaven Fruit}

Hormone treatments were performed at $22^{\circ} \mathrm{C}$ on Redhaven (RH) fruits at S3II, corresponding to 95 days after full bloom (dAFB), attached to a branch that was kept in water. The auxin treatment was performed by dipping the whole fruit in 1-naphthalene acetic acid [NAA, 2 mmol L ${ }^{-1}$ added with Silwet L-77 $\left(200 \mu \mathrm{L} \mathrm{L}^{-1}\right)$ as surfactant] for $15 \mathrm{~min}$; thereafter, fruit were sprayed with the NAA solution every $12 \mathrm{~h}$ over a period of $48 \mathrm{~h}$ (NAA omitted in the mock control). The ethylene treatment was instead carried out by placing whole fruit in a sealed chamber and flushing them with ethylene $\left(10 \mu \mathrm{L} \mathrm{L}^{-1}\right)$ in air at a flow rate of approximately $6 \mathrm{~L} \mathrm{~h}^{-1}$ as previously described in Tadiello et al. (2016). At the end of treatment ( $48 \mathrm{~h}$ ), mesocarp tissues from a pool of 12 fruit per class were frozen in liquid nitrogen and stored at $-80^{\circ} \mathrm{C}$ until used.

\section{1-MCP Treatments on Stark Red Gold Fruit}

Stark Red Gold (SRG) peaches were harvested at 123 dAFB (S4), i.e., at commercial maturity date, which is about 2 weeks later than that of RH. In order to obtain homogeneous fruit at different 
stages of ripening, fruits were graded immediately after harvest into three classes by decreasing ranges of the index of absorbance difference $\left(\mathrm{I}_{\mathrm{AD}}\right.$; class 0 : $\mathrm{I}_{\mathrm{AD}} 1.2-0.9$; class 1 : $\mathrm{I}_{\mathrm{AD}} 0.9-0.6$; class 2: $\mathrm{I}_{\mathrm{AD}}$ 0.6-0.3), as previously described (Ziosi et al., 2008). According to previous studies (Ziosi et al., 2008), fruit from the three classes could be classified as belonging to pre-climacteric (class 0 ), onset of climacteric (class 1), and full climacteric (class $0)$ stages of the ripening process. Fruits from each class were treated or not (controls) with 1-methylcyclopropene (1-MCP). Treatment was carried by placing one hundred fruits per class in two sealed 30-L plastic jars (50 fruit each). SmartFresh ${ }^{\mathrm{TM}}$ (AgroFresh Inc., Philadelphia, PA, United States), a commercial powder containing $0.14 \%(\mathrm{w} / \mathrm{w})$ - 1 -MCP a.i., was prepared as a 10-fold concentrated stock solution following the technical bulletin of the company, and injected as $10 \mathrm{~mL}$ of air (final concentration $1 \mathrm{~mL} \mathrm{~L}^{-1}$ equivalent to $\left.1 \mu \mathrm{L} \mathrm{L}^{-1}\right)$. The same total number of fruit per class was kept in two sealed jars for $12 \mathrm{~h}$ at $25^{\circ} \mathrm{C}$ without 1 -MCP (air controls). Treated and control fruit were then transferred to a growth chamber at $25^{\circ} \mathrm{C}$. At the end of treatment $(12 \mathrm{~h})$ and at each following sampling time, mesocarp tissues from a pool of 10 fruit per class were frozen in liquid nitrogen and stored at $-80^{\circ} \mathrm{C}$ until used, as described in Tadiello et al. (2016).

\section{RNA Extraction and Expression Analyses by Quantitative Real Time PCR (qRT-PCR)}

Peach RNA was prepared from a frozen powder obtained by grinding mesocarp sectors from at least four different fruits. From $4 \mathrm{~g}$ of this powder, total RNA was extracted following a protocol previously described (Chang et al., 1993). Arabidopsis RNA was extracted from wild type and 35S::CTG134 mutant seedlings, using the LiCl method (Verwoerd et al., 1989). Expression analyses were performed using Power SYBR Green PCR Master Mix (Applied Biosystems). Normalization was performed using UBIQUITIN10 (UBI10) and ACTIN8 as internal standards for Arabidopsis and Ppa009483m/Prupe.8G137600 for peach (Primers are listed in Supplementary Table 1). qRT-PCR was performed and the obtained data manipulated as previously described (Trainotti et al., 2007).

\section{In Situ Hybridizations}

Prunus persica S3II and S4 fruits were fixed and embedded in $4 \%$ paraformaldehyde. A CTG134 specific probe was amplified by PCR from S3II and S4 fruit cDNAs (primers listed in Supplementary Table 1) and further cloned in pGEM T-easy vector (Promega). The CTG134 transformed vector was further used as template for the creation of sense and antisense probes by an in vitro transcription performed with SP6 and T7 polymerases. Sections of plant tissue were probed with digoxigenin-labeled antisense RNA-probe as previously described (Brambilla et al., 2007) and observed with a Zeiss Axiophot D1 light microscope ${ }^{1}$.

${ }^{1}$ http://www.zeiss.com

\section{pPR97-proCTG134:GUS Construct Design and GUS Assays}

To assess the CTG134 promoter activity, a fragment of 2679 bp located upstream of the coding sequence initiation site (Supplementary Figure 1A) was isolated from peach genomic DNA (cv. Red Haven) by PCR. PCR product was cloned into the pCR8/GW/TOPO TA Cloning vector (Invitrogen, Carlsbad, CA, United States), according to the manufacturer's instructions and confirmed by sequencing. The promoter fragment was thus subcloned into a pPR97-derived vector $(12.20 \mathrm{~kb})$, made compatible with the Gateway cloning system (LR Clonase II - Invitrogen, Carlsbad, CA, United States). This modified pPR97 vector with kanamycin resistance was employed for stable transformations both in A. thaliana and N. tabacum, to measure the CTG134 promoter activity. The promoter was tested by cloning the upstream sequence and a GUS reporter gene interrupted by a plant intron (Vancanneyt et al., 1990). To make easier the cloning, a CC_rfA gateway cassette was inserted (SmaI) upstream of the reporter gene and the antibiotic kanamycin was used to select resistant successfully transformed plants. For the GUS histochemical assay (Jefferson et al., 1987), tissues were cut and immersed into $1 \mathrm{mM}$ X-Gluc (5-bromo-4-chloro-3-indolyl $\beta$-D-glucuronide), $100 \mathrm{mM}$ phosphate buffer $\mathrm{pH} 8.5,0.1 \%(\mathrm{v} / \mathrm{v})$ Triton X-100, $0.5 \mathrm{mM}$ $\mathrm{K}_{3} \mathrm{Fe}(\mathrm{CN})_{6}, 0.5 \mathrm{mM} \mathrm{K} \mathrm{K}_{4} \mathrm{Fe}(\mathrm{CN})_{6}, 10 \mathrm{mM}$ EDTA, 20\% (v/v) methanol. After a vacuum treatment of $5 \mathrm{~min}$ to facilitate the penetration of the dying solution, tissues were kept for $12 \mathrm{~h}$ in the dark at $37^{\circ} \mathrm{C}$. Samples were then fixed and destained with $50 \%$ acetic acid in methanol and stored in $70 \%(\mathrm{v} / \mathrm{v})$ ethanol. For the enzymatic GUS assays, proteins were extracted in $1.7 \mathrm{ml} / \mathrm{g}$ fresh weight of modified CCRL buffer $(100 \mathrm{mmol} / \mathrm{L}$ K-phosphate $\mathrm{pH} 7.8,1 \mathrm{mmol} / \mathrm{L}$ EDTA, $10 \%$ glycerol) added before use with $7 \mathrm{mmol} / \mathrm{L} \beta$-mercaptoethanol and $0.1 \%$ Triton X-100, (Luehrsen et al., 1992). The homogenate was centrifuged twice for $15 \mathrm{~min}$ and the clear supernatant was used for either protein (Bradford, 1976) or reporter activity quantification. The GUS assay was carried out by incubating 50-200 $\mu \mathrm{L}$ of protein extract with the substrate 4-methylumbelliferyl- $\beta$-D-glucuronide (MUG) at $37^{\circ} \mathrm{C}$. The released 4 -methylumbelliferone (4-MU) was quantified with a Hoefer TKO 100 mini-fluorometer according to the manufacturer's instructions. The GUS activity was expressed as nmol 4-MU released in a minute per microgram of protein.

\section{pGreen-AmpR-KanNos-35S:CTG134 Construct Design}

The CTG134 coding sequence (524 bp) was amplified by PCR from $P$. persica (cv. Red Haven, S4I development stage) cDNA and subsequently cloned into the pCR8/GW/TOPO TA Cloning vector (Invitrogen, Carlsbad, CA, United States). The CTG134 CDS was further inserted into a pGreen-derived vector (Hellens et al., 2000) with the Gateway cloning system (LR Clonase II - Invitrogen, Carlsbad, CA, United States). The pGreen-derived vector was modified to confer resistance to both kanamycin and ampicillin. Moreover, a CC_rfA gateway cassette was inserted downstream of the 35 S promoter in the EcoRV site. 
As before, the selection of plants was carried out with kanamycin (Supplementary Figure 1B).

\section{Arabidopsis thaliana and Tobacco Transformation}

Single PCR-positive Agrobacterium GV3101 colonies were used to grow liquid cultures for the transformation of $A$. thaliana Columbia 0 plants with the floral dip method (Clough and Bent, 1998). The first flowers of 4 -weeks old plants were cut to allow, after 4-8 days, the growing of a second set, further dipped in a suspension of Agrobacterium cells $\left(\mathrm{OD}_{600}=0.8\right)$, sucrose $(5 \% \mathrm{~m} / \mathrm{v})$ and Silwet L-77 $(0.05 \%)$. Plants were incubated in the dark for $16 \mathrm{~h}$ before a second growing phase in growth chamber (16/8 light/dark cycle, $25^{\circ} \mathrm{C}, 70 \%$ relative humidity) until seeds were obtained. Transformed plants were screened on solid $1 / 2$ MS medium (MS salts with vitamins $2.17 \mathrm{~g} / \mathrm{L}$, sucrose $15 \mathrm{~g} / \mathrm{L}, \mathrm{pH}$ 5.75) supplemented with kanamycin (50 mg $\left.\mathrm{L}^{-1}\right)$. After 1 week, the resistant plants were planted into soil and grown in greenhouse for at least two generations, until T-DNA insertions reached homozygosity. Plants were screened for the presence of the transgene by PCR on genomic DNA using specific primer pairs. In vitro grown
N. tabacum SNN plants were instead transformed following the protocol reported by (Fisher and Guiltinan, 1995). As for Arabidopsis, plants were screened for the presence of the transgene with PCR on genomic DNA using specific primer pairs.

\section{Peptide Synthesis}

The peptides DYSPARRKPPIHN and DY $\left(\mathrm{SO}_{3} \mathrm{H}_{2}\right)$ SPARRKPPIHN were synthesized by automatic solid phase procedures. The synthesis was performed using a multiple peptide synthesizer (SyroII, MultiSynTech GmbH) on a pre-loaded Wang resin (100-200 mesh) with $\mathrm{N}$ $\alpha$-Fmoc- $N$ - $\beta$-trityl-l-asparagine (Novabiochem, Bad Soden, Germany). The fluoren-9-ylmethoxycarbonyl (Fmoc) strategy (Fields and Noble, 1990) was used throughout the peptide chain assembly, utilizing O-(7-azabenzotriazol-1yl)- $N, N, N^{\prime}, N^{\prime}$-tetramethyluronium hexafluorophosphate (HATU) as coupling reagent (Carpino et al., 2001). The side-chain protected amino acid building blocks used were: $N$ - $\alpha$-Fmoc- $\beta$-tert-butyl-1-aspartic acid, $\quad N$ - $\alpha$-Fmoc- $N \varepsilon$-tertbutyloxycarbonyl-1-lysine, $N$ - $\alpha$-Fmoc- $N \omega$-2,2,4,6,7-pentamethyl dihydrobenzofuran-5-sulfonyl-1-arginine, $\quad N$ - $\alpha$-Fmoc-O-tert-
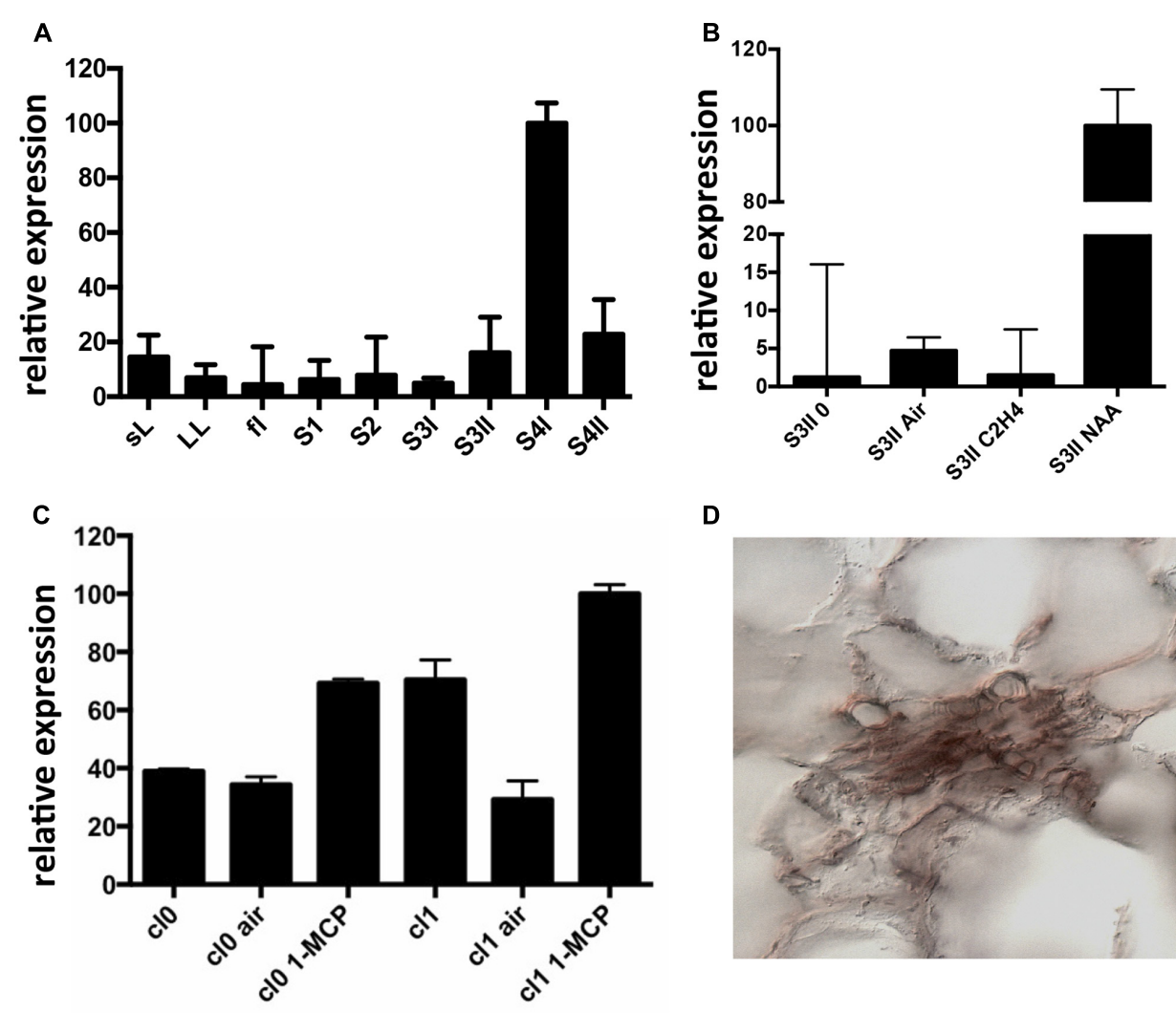

D

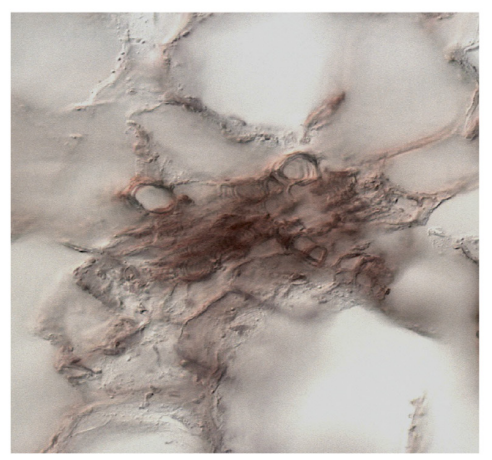

FIGURE 1 | Expression profile of CTG134. (A) CTG134 expression was barely detectable, by qRT-PCR, in non-fruit organs (small expanding leaves -sL- and fully developed leaves -LL-) and in fruit at early development (stage 1 and 2, -S1, S2-). In mature fruit (S3II) there was a sharp increase in CTG134 transcription (S4I), slightly ceasing after the ethylene peak (S4II). (B) Ethylene, auxin and 1-MCP responsiveness of CTG134. CTG134 expression, barely detectable in mature preclimacteric fruit (S3II 0) was strongly increased upon auxin (NAA, 1-naphthalene acetic acid, a synthetic auxin) but not ethylene treatment. (C) Both in Class 0 and Class 1 S4 fruit, 1-MCP upregulated CGT134 expression. (D) Localization of CTG134 expression in peach mesocarp by in situ hybridization. In peach mesocarp at S4, CTG134 expression was mainly associated with vascular bundles (control sections in Supplementary Figure 2). Scale bar $=50 \mu \mathrm{m}$. 

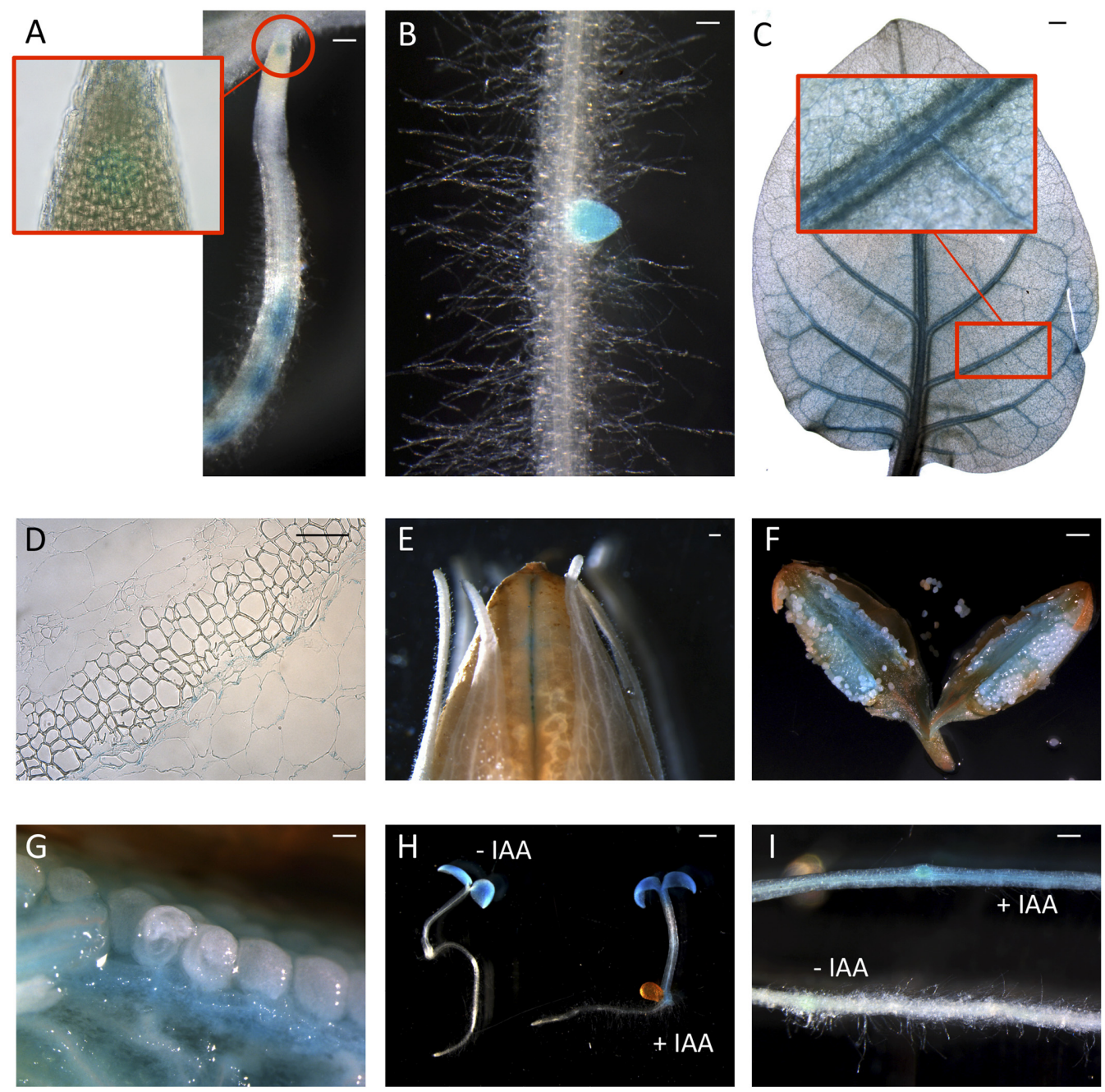

FIGURE 2 | ProCTG134:GUS expression in tobacco and auxin responsiveness. (A,B) In tobacco roots the expression of GUS was detected at the level of the RAM (inset) but mainly at the level of lateral root primordia. (C) Staining was detectable also in leaves, especially if treated with $50 \mu \mathrm{M} I \mathrm{IAA}$, and particularly in veins (inset). (D) In the stem, GUS expression was more abundant in parenchymatic cells of the vascular tissue. In the fruit expression was visible at the dehiscence zone (E) and in the placenta $(\mathbf{F}, \mathbf{G})$. (H) Auxin responsiveness in 1-week-old representative seedlings (untreated on the left, and treaded with $50 \mu \mathrm{M} \mathrm{IAA}$ on the right) and in the root (I, untreated, on the bottom, and treaded with $50 \mu \mathrm{M} \mathrm{IAA}$, on the top). Scale bar in (B,C,F) $=500 \mu \mathrm{m}$, in (A) $=200 \mu \mathrm{m}$, in (D) $=100 \mu \mathrm{m}$ and in (E) $=1000 \mu \mathrm{m}$.

butyl-1-serine, $\quad N-\alpha$-Fmoc-N(im)-trityl-l-histidine, $\quad N$ - $\alpha$-Fmoc$O$-tert-butyl-1-tyrosine and $\mathrm{N}-\alpha$-Fmoc-O-sulfo-l-tyrosine tetrabutylammonium salt. Cleavage of the peptides was performed by incubating the peptidyl resins with trifluoroacetic acid/H2O/triisopropylsilane $(95 \% / 2,5 \% / 2,5 \%)$ for $2.5 \mathrm{~h}$ at $0^{\circ} \mathrm{C}$. Crude peptides were purified by a preparative reverse phase HPLC. Molecular masses of the peptide were confirmed by mass spectroscopy on a MALDI TOF-TOF using a Applied Biosystems 4800 mass spectrometer.

\section{$\mathrm{Ca}^{2+}$ Measurement Assays}

$\mathrm{Ca}^{2+}$ measurement assays were carried out in cell suspension cultures obtained from Arabidopsis seedlings stably expressing cytosolic aequorin (seeds kindly provided by M.R. Knight, Durham, United Kingdom). Reconstitution of aequorin and
$\mathrm{Ca}^{2+}$ measurements were carried out as described by (Sello et al., 2016).

\section{RESULTS}

\section{Regulation of CTG134 Expression}

Expression of CTG134 was assessed in peach mesocarp during the onset of fruit ripening (i.e., at early stage $4-\mathrm{S} 4 \mathrm{I}$ - Figure 1A). CTG134 mRNA accumulated in preclimacteric fruit (i.e., S3II) after auxin treatment, while exogenous ethylene had no effect (Figure 1B). Moreover, treatment with the ethylene inhibitor 1MCP induced CTG134 transcription at stages before (cl 0) and coincident ( $\mathrm{cl} 1$ ) with the full climacteric (Figure 1C). The peach mesocarp at ripening is mainly made up of parenchymal cells and vascular tissue (Zanchin et al., 1994). To localize the types 

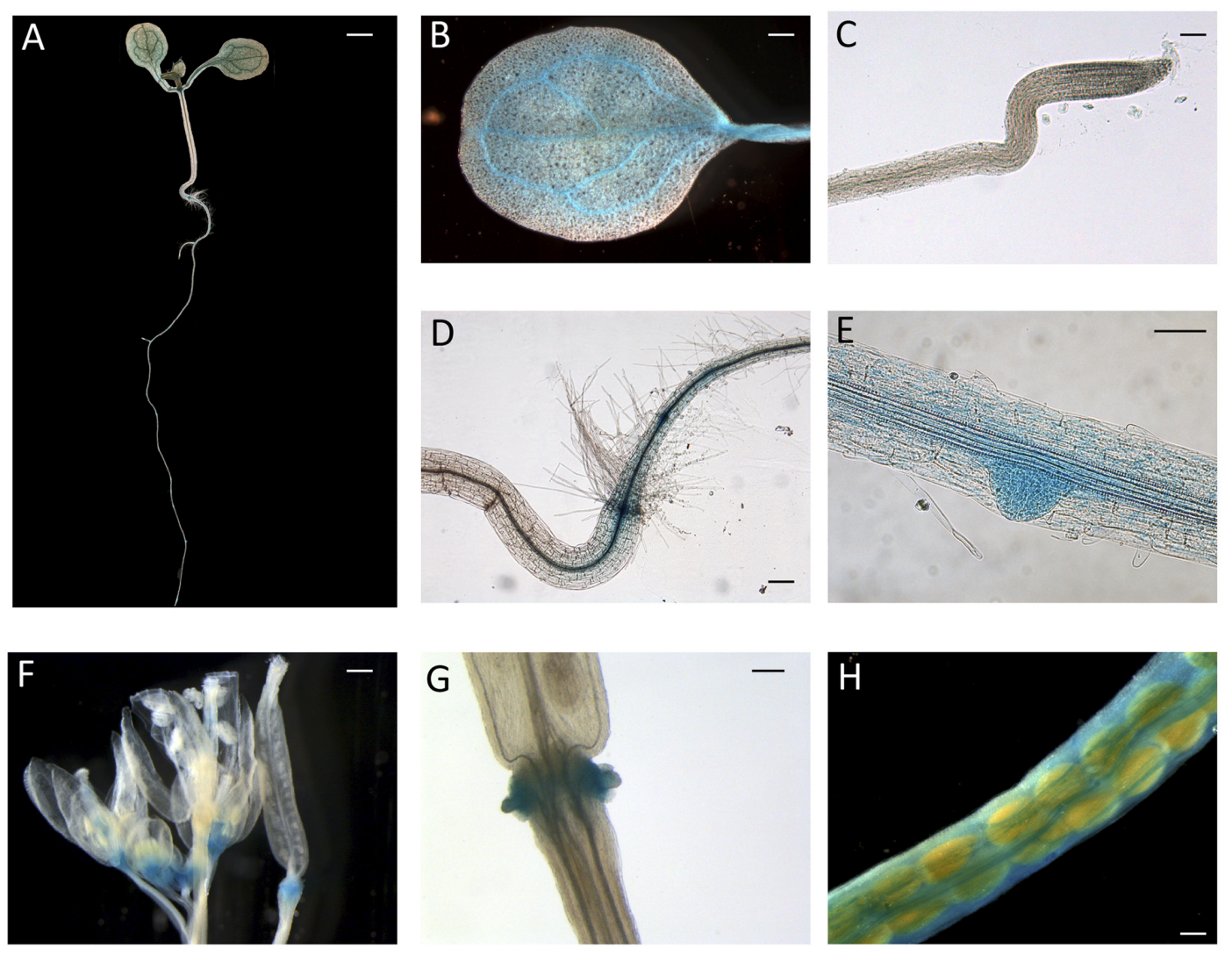

FIGURE 3 | ProCTG134:GUS expression in Arabidopsis. At 7 days after germination (A), GUS staining is detectable in cotyledons, especially in veins (B), at the root-shoot transition zone (D) and in lateral root primordia (E), while is barely detectable in RAM (C). In the reproductive part, expression was detected in abscission zones before (F) and after (G) organ shedding. Expression was detectable also in maturing siliques mainly associated with vascular bundles (H). Scale bar in $(\mathbf{B}, \mathbf{C}, \mathbf{F})=500 \mu \mathrm{m}$, in $\mathbf{( A )}=200 \mu \mathrm{m}$, in $\mathbf{( D )}=100 \mu \mathrm{m}$ and in $\mathbf{( E )}=1000 \mu \mathrm{m}$.

of cells expressing CTG134 at ripening, in situ hybridization experiments were carried out with mesocarp sections prepared by peach fruit in S4 stage. The CTG134 mRNA was localized in vascular bundles (Supplementary Figure 2C), most likely in the phloem or parenchymal cells (Figure 1D).

Since peach is a recalcitrant species to transform, proCTG134:GUS lines were generated in both tobacco and Arabidopsis model species. In tobacco, a slight but evident GUS staining was detected in the apical meristem (RAM) of in vitro grown lateral roots (Figure 2A). Moreover, a dark staining was visible in lateral root emergence (Figure 2B) as well as in leaf, mainly associated, but not limited to, the vascular tissue (Figure 2C). In the stem of 1-week-old plantlets, GUS expression was localized in phloem of cell layers closed to the cambium (Figure 2D). GUS expression was also tested in reproductive organs, where it was detected in the tips of both young sepals and petals (not shown) and in capsules at the level of the dehiscence zone (Figure 2E). The inner part of the fruit was the part more significantly stained (Figures 2F,G), with the highest expression in the placenta (Figure 2G). On the contrary, in all the transgenic lines investigated in this study, the GUS coloration was never observed in ovule. In 1 -week-old tobacco seedlings the reporter was more expressed in cotyledons than roots. However, 5-h treatment with $50 \mu \mathrm{M}$ IAA induced a different GUS staining in the entire shoot apex and root, reaching the highest intensity in the root-stem transition zone (Figure 2H). A similar auxin-induced expression was also observed in roots of in vitro grown plantlets (Figure 2I). The stimulation of the GUS staining in tobacco finds also consistency with the aforementioned expression pattern of CTG134 in peach fruit. The expression of this element was in fact enhanced by auxin (Figure 1B) and auxin responsive elements (AREs) were moreover detected in the CTG134 promoter region (Supplementary Figure 1B). To further validate the heterologous analysis carried out in tobacco, the activity of the CTG134 promoter was additionally investigated in Arabidopsis (Figure 3A). Also in this species, the GUS expression was higher in cotyledons (Figure 3B) rather than in primary root, where the GUS staining was undetectable in the RAM (Figure 3C). The GUS activity was instead clearly visible at the root-stem transition zone (Figure 3D) and during lateral root emergence (Figure 3E). In the reproductive organs, the expression pattern was detected in abscission zones before (Figure 3F) and after (Figure 3G) shedding. The expression was also detected in maturing siliques and leaves, especially in those associated with vascular bundles (Figure $3 \mathbf{H}$ ). 


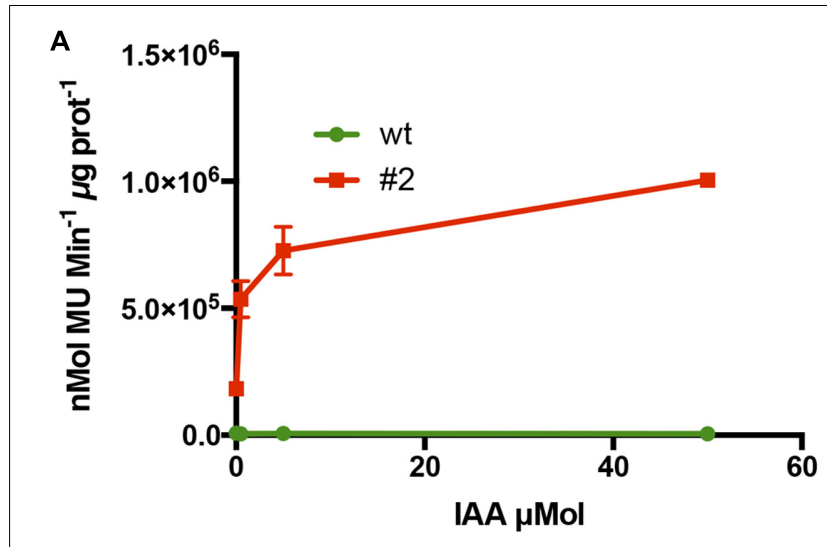

B

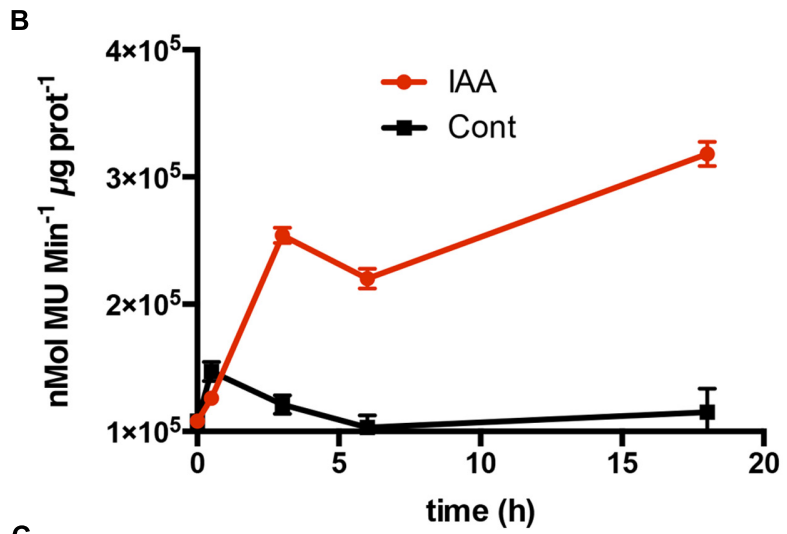

C

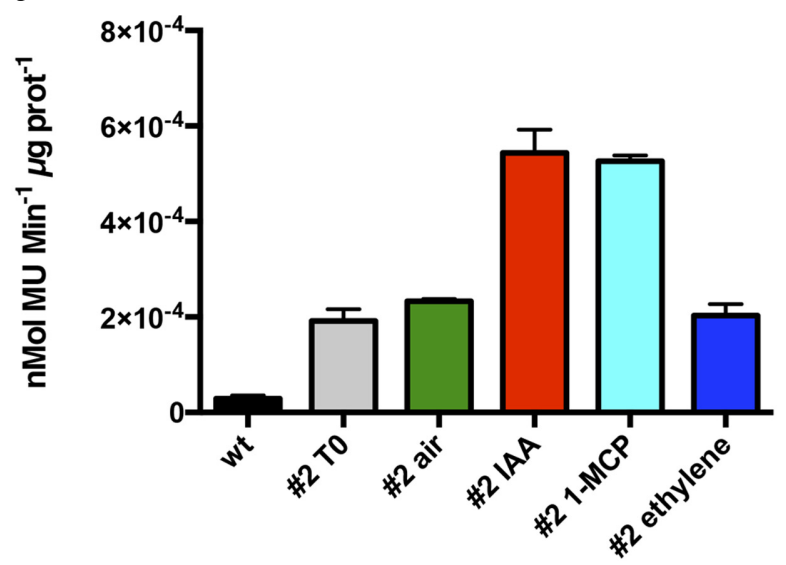

FIGURE 4 | Hormone responsiveness of ProCTG134:GUS in tobacco seedlings. (A) Auxin was effective in inducing the promoter of CTG134 already at $0.5 \mu \mathrm{M}$, to reach almost complete saturation at $50 \mu \mathrm{M}$. (B) Saturation of the auxin induction after $3 \mathrm{~h}$. (C) Besides auxin, also 1-MCP had an inductive effect on the promoter of CTG134, while ethylene seemed ineffective. All experiments were carried out with T3 seedlings of line \#2.

\section{Hormonal Regulation of CTG134 in Tobacco}

To test whether the auxin responsiveness was due to the promoter regulatory region, 1-week old tobacco seedlings of line \#2 were exposed to increasing concentrations of IAA. The CTG134 promoter was responsive to IAA already at $0.5 \mu \mathrm{M}$, with an activity pattern proportional to the hormone concentrations. The system reached saturation at $50 \mu \mathrm{M}$ (Figure 4A). The IAA induction kinetic was assessed over a time course of $20 \mathrm{~h}$ on tobacco seedlings of line \#2 treated with $10 \mu \mathrm{M}$ IAA. An initial slight induction in both control and treated samples was observed already after $30 \mathrm{~min}$, after which the GUS activity remained at a basal level in the control, while in the IAA treated samples a significant burst was observed after $3 \mathrm{~h}$ after the treatment (Figure 4B). Since in peach fruit the expression of CTG134 was insensitive to ethylene and induced by 1-MCP (Figures 2B,C), the promoter responsiveness was tested by treating 10-day-old tobacco seedlings for $16 \mathrm{~h}$ with ethylene $\left(10 \mu \mathrm{L} \mathrm{L}^{-1}\right)$, IAA $(10 \mu \mathrm{M})$ and 1-MCP $\left(1 \mu \mathrm{L} \mathrm{L}^{-1}\right)$. 1-MCP induced the reporter activity similarly to auxin (Figure 4C), while treatment with ethylene did not change the expression of the GUS reporter gene.

\section{Over-Expression of CTG134 in Tobacco}

To functionally investigate the role of the CTG134 peptide, its full-length coding sequence, under the control of the Cauliflower mosaic virus $35 \mathrm{~S}$ (35S CaMV) promoter was expressed in tobacco. The development of longer root hairs was noticed already in the early phases of transgenic plant production (Figure 5A). A YFP gene, cloned in the same binary vector as CTG134, was overexpressed to have control plants able to grow on kanamycin and gentamicin present in the growth media. To further assess this phenotype, scions from different clones were propagated and primary roots from 30 day-old plants were analyzed by taking images in the root portion located at $6 \mathrm{~mm}$ from the root tip. On average, the CTG134 overexpressing lines showed an increase of at least twofold in root hair length (ANOVA, $F=87.75, d f=155, p<0.001$ ) with respect to control wild type plants (Figure 5B). The effect on root development was also evident during adventitious roots formation in in vitro plants (Figures 6A,B). Indeed, root primordia emerged earlier in 35S:CTG134 scions than in controls, although the root growth was slower, resulting at the end in shorter roots (Figure 6C). Within the hypothesis of the auxin-ethylene crosstalk, the putative mediating role of CTG134 was investigated exposing to ethylene $\left(10 \mu \mathrm{L} \mathrm{L}^{-1}\right)$ 35S:CTG134 transformed tobacco seedlings grown in the dark. Environmental Scanning Electron Microscopy (ESEM, Figures 7A-D), confirmed the difference in the root hair phenotype, but a clear distinction between transgenic lines and controls for the apical hook and hypocotyl thickening, typical of the triple ethylene response, was not observed. Indeed, the untreated (air) 35S:CTG134 (Figure 7C) seedlings displayed a phenotype similar to controls grown in presence of ethylene (Figure 7B), despite the fact that samples were partially dehydrated by the light vacuum imposed during the ESEM observation. Interestingly, the ethylene treatment induced an additional phenotype in the 35S:CTG134 lines, provoking the development of a massive root hair formation, completely wrapping the root body (Figure 7D). Scanning Electron Microscopy (SEM) analyses disclosed that the previously observed root hair phenotype was due not only to an increase of their length but also of their density in the 35S:CTG134 lines (Figure 7E) compared to control (Figure 7F). Indeed, most of the root epidermal cells of 35S:CTG134 seedlings 
A

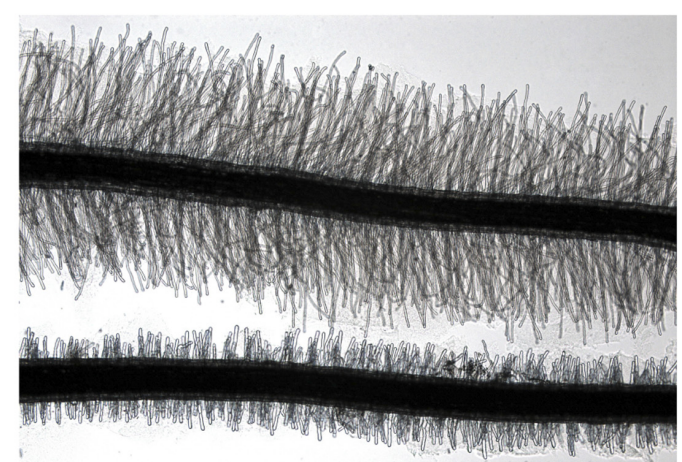

B

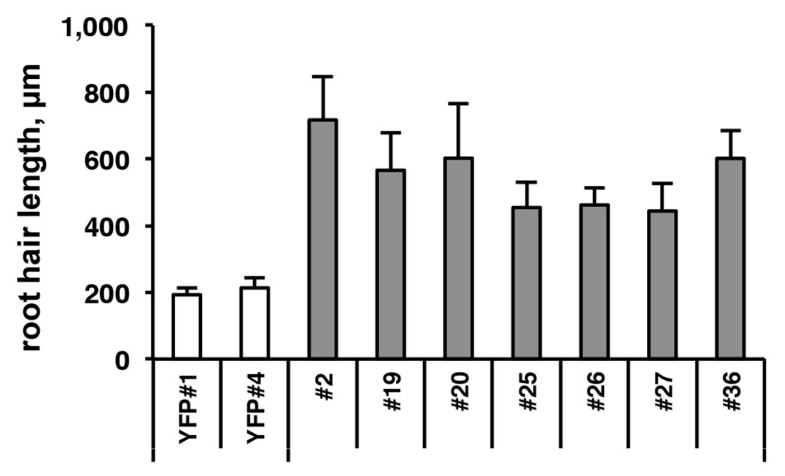

FIGURE 5 | Effects on root growth of CTG134 overexpression in tobacco.

(A,B) CTG134 increases hair length (ANOVA, $F=87.75, d f=155, p<0.001$ ) in tobacco plantlets grown on agar (controls are transgenic plants expressing the YFP reporter, on bottom in $\mathbf{A}$ ).

developed root hairs, while in WT trichoblasts were arranged in alternating files with atrichoblasts along the root surface.

Since the CTG134 sequence was originally isolated from peach fruit, and placenta cells were stained in tobacco plants expressing the GUS reporter gene driven by the CTG134 promoter, tobacco transgenic capsules were also analyzed. Even if tobacco produces a dry fruit structurally different from the fleshy stone fruit of peach, the CTG134 overexpression led to a detectable increase in fruit size. Tobacco capsules of 35S:CTG134, harvested 12 days after anthesis (before drying), showed an increase in diameter of about $16 \%$ with respect to wild type or 35S:YFP (ANOVA, $F=3,85, d f=22, p=0.013$ ) (Figure 8).

\section{Over-Expression of CTG134 in Arabidopsis}

Similarly to tobacco, the same construct was further employed to transform Arabidopsis. T2 CTG134 overexpressing lines were easily identified for their root phenotype when grown on horizontal plates. The primary root of 5-day-old 35S:CTG134 seedlings had indeed longer hairs than WT ones (Figure 9A). Moreover, root hairs developed closer to the apex that in WT roots. Consequently, the hairless portion of the root was about
A

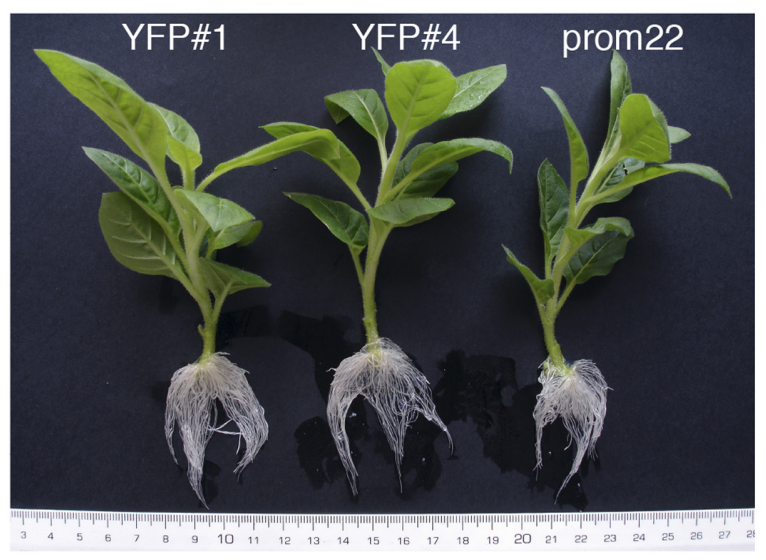

B

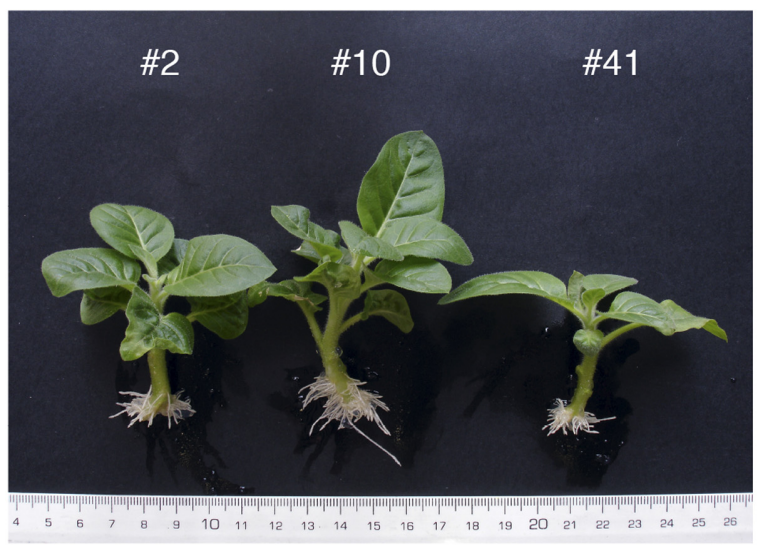

C

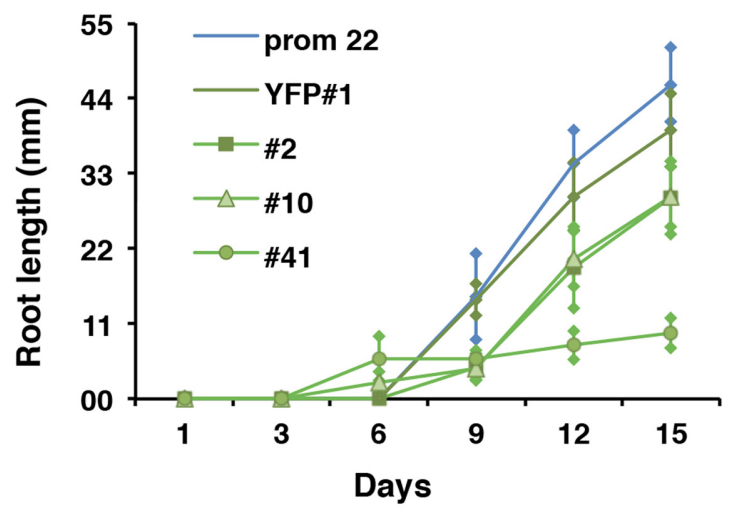

FIGURE 6 | Effects on adventitious root formation of CTG134 overexpression in tobacco. (A) control lines; (B) 35S:CTG134 tobacco clones. Controls were YFP expressing clones (YFP\#1 and YFP\#4) and ProCTG134:GUS line (prom 22). (C) CTG134 overexpression caused faster development of adventitious roots but inhibited their growth.

half (ANOVA, $F=101.1, d f=23, p<0.001$ ) of that in the WT (Figure 9B). As regards to root hair length, being not uniform along the root and clearly depending on age, sizes were taken at given distances from the root-stem transition zone and in a region of the tip that was determined to be, based on growth rate, 4 -day old. Both measures clearly indicated that the root hairs in the overexpressing lines were longer (ANOVA, 

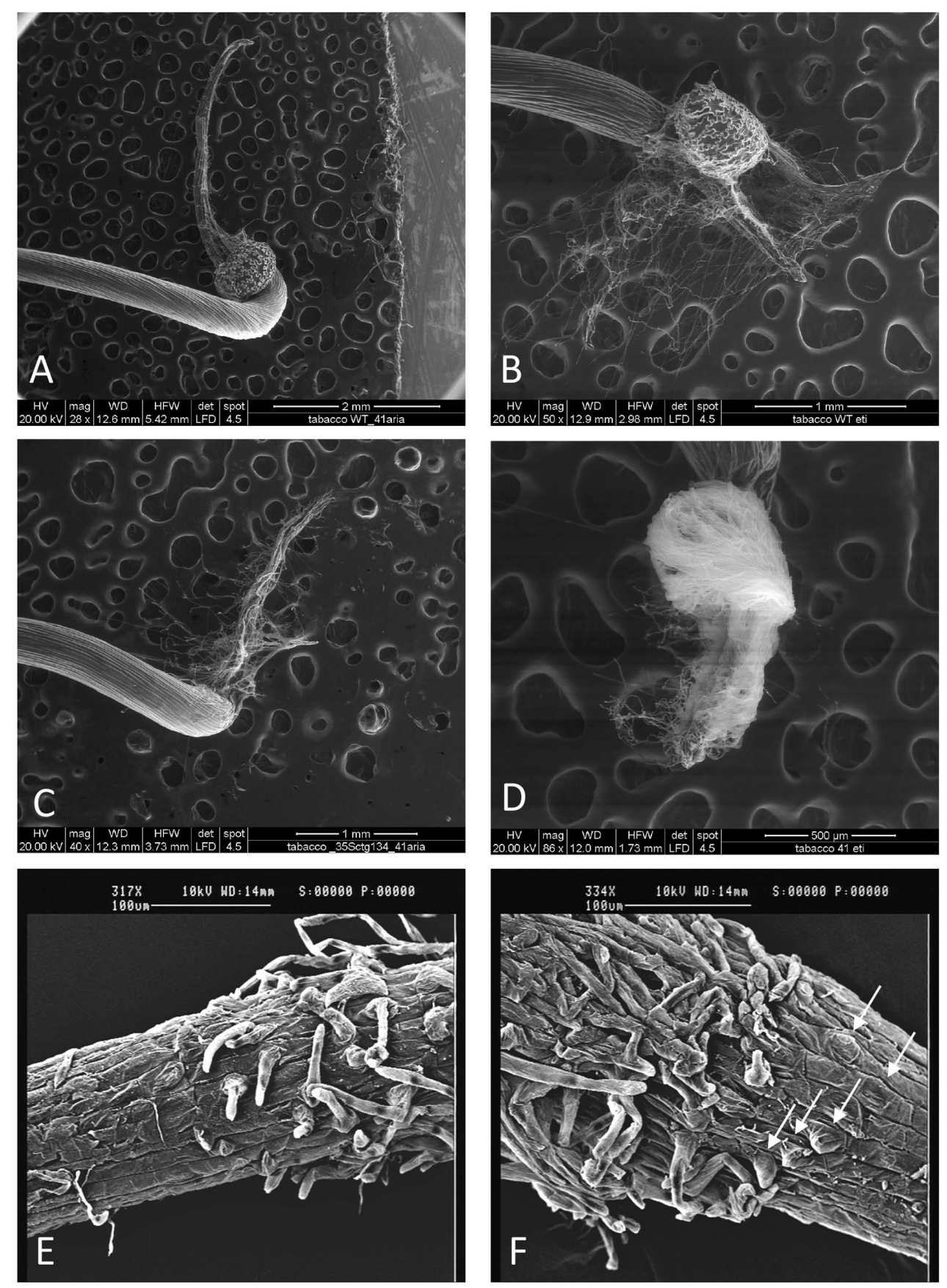

FIGURE 7 | Effects on root growth of CTG134 overexpression in tobacco seedlings. CTG134 overexpression in tobacco did not saturate ethylene effect on root hair development and changed the developmental fate of epidermal cells. WT (A,B,E) and 35S:CTG134 (C,D,F) seedling roots were imaged by ESEM after growth in air (A,C) or ethylene (B,D). SEM images of the transition zones of tobacco etiolated seedling roots grown in air showed trichoblasts and atrichoblasts in the WT (E) while almost all epidermal cells were trichoblasts in 35S:CTG134 plants (F; white arrows indicate the presence of root hair primordia that are emerging from epidermal cells).

$F=95.07, d f=342, p<0.001 ;$ ANOVA, $F=98.31, d f=342$, $p<0.001$, respectively) than wild type (Figure 9C). Members of the RGF/GLV family in Arabidopsis are known to induce developmental defects in roots when over-expressing seedlings were grown on tilted plates (Whitford et al., 2012; Fernandez et al., 2013). Accordingly, in this work Arabidopsis 35S:CTG134 seedlings produced roots with larger and more irregular waves than the WT (Figure 10A). This effect could be phenocopied by the WT when the synthetic CTG134 peptide (pCGT134) was added to the medium, with the sulfated form being more 


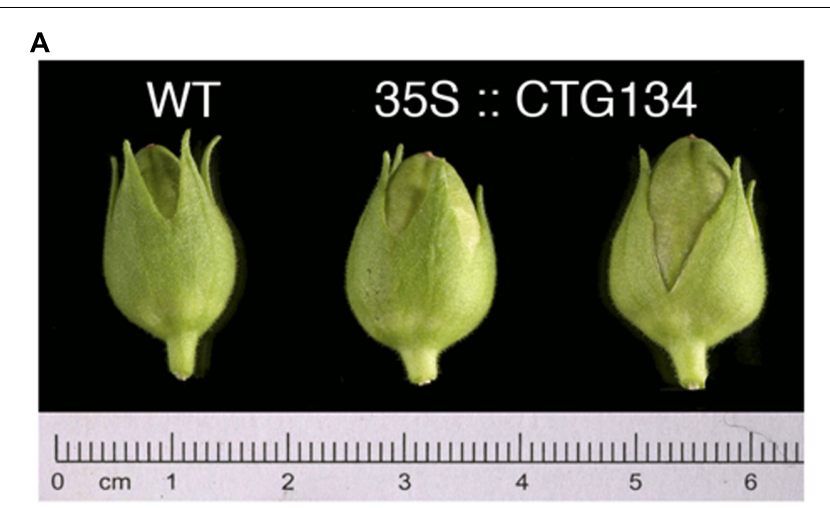

B

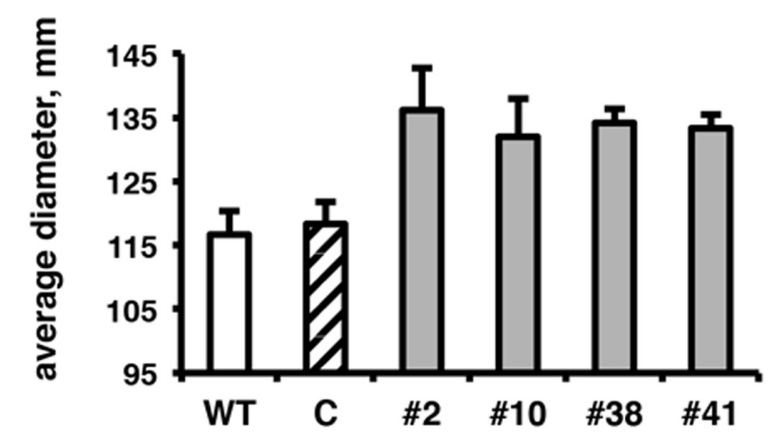

FIGURE 8 | Effects on capsule size of CTG134 overexpression in tobacco. (A) Representative capsules collected from tobacco plants 12 days post-anthesis. (B) The capsule diameter of CTG134 overexpressing lines was larger than that of WT or control (ProCTG134:GUS) transgenic lines.

active than the non-sulfated one (Figure 10A). Albeit the hairless portion of the root was shorter in overexpressing seedlings, the meristematic region of the root was longer. Moreover, both 35S:CTG134 lines and WT seedlings grown in a medium supplemented with pCTG134 had an increase in root meristem size (Figures 10B,C). The effect on the root meristem size was saturable, as overexpressing lines did not respond to exogenous pCTG134 as the WT (Figure 10C).

The effect of CTG134 overexpression at the transcriptional level was tested on 5-day-old seedling roots (Figure 11). Alteration in root hairs morphology and quantity was accompanied with a reduction of GLABRA2 (GL2) and a slight induction of CAPRICE (CPC) expression. The increased meristem size was supported by the expression of CYCLIN $B 1 ; 1(C Y C B 1 ; 1)$. The development of root hair was selected as a suitable developmental process to test the effect of CTG134 on the interactions between ethylene and auxin occurring at the onset of peach ripening, since the crosstalk of the two hormones during root hair development is well documented (reviewed by Van de Poel et al., 2015). The expression of the ethylene biosynthetic gene ACS2 was induced in roots of 35S:CTG134 seedlings (Figure 11), as well as that of ETR1 and $E I N 3$, encoding an ethylene receptor and a transcription factors starting the transcriptional cascade leading to ethylene responses,
A

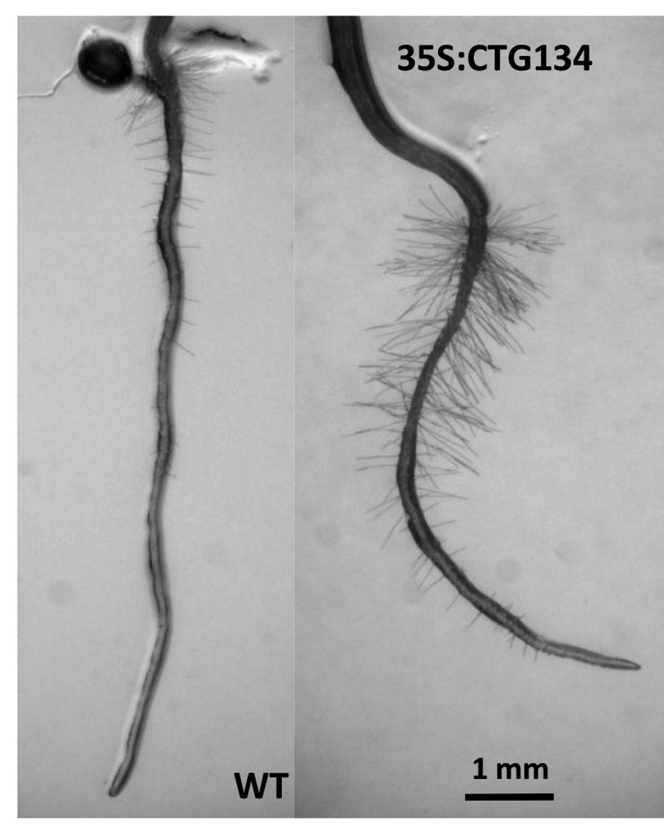

B
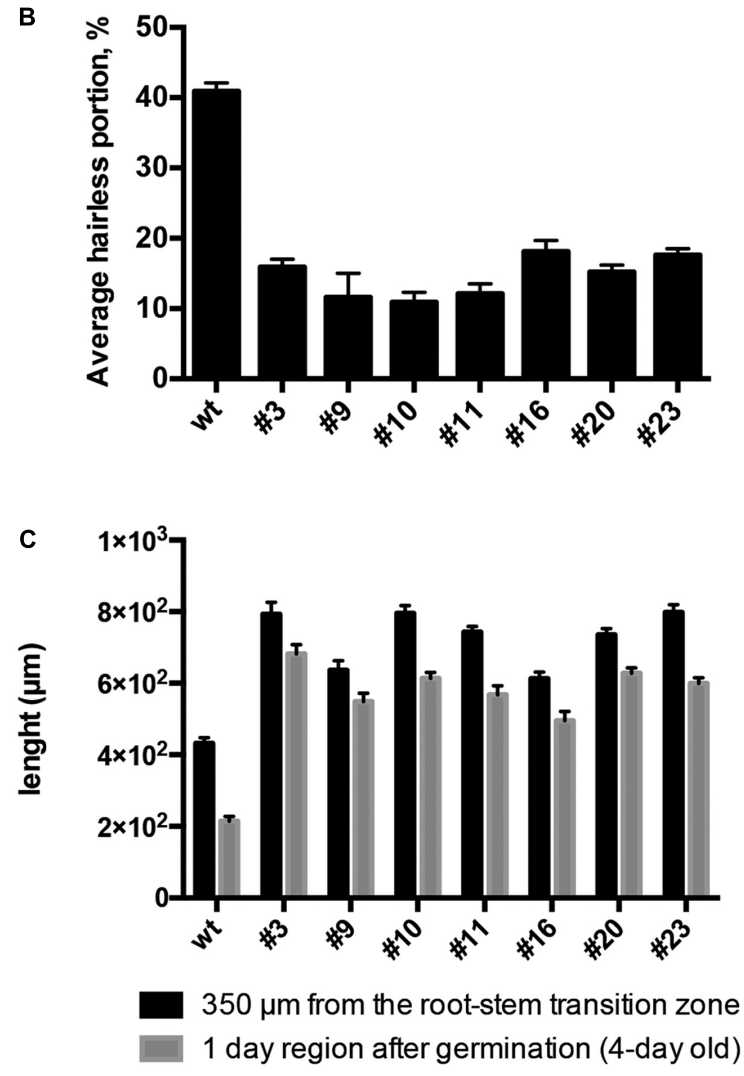

FIGURE 9 | Effects on root development of CTG134 overexpression in Arabidopsis. CTG134 increased hair length (Measurements at $350 \mu \mathrm{m}$ from the root-stem transition zone: ANOVA, $F=95.07, d f=342, p<0.001$; Measurements at 1 day region after germination: ANOVA, $F=98.31$, $d f=342, p<0.001$ ) in Arabidopsis plantlets grown on agar (A,C); moreover, the portion without root hairs was reduced (ANOVA, $F=101.1, d f=23$, $p<0.001)(\mathbf{A}, \mathbf{B})$. 

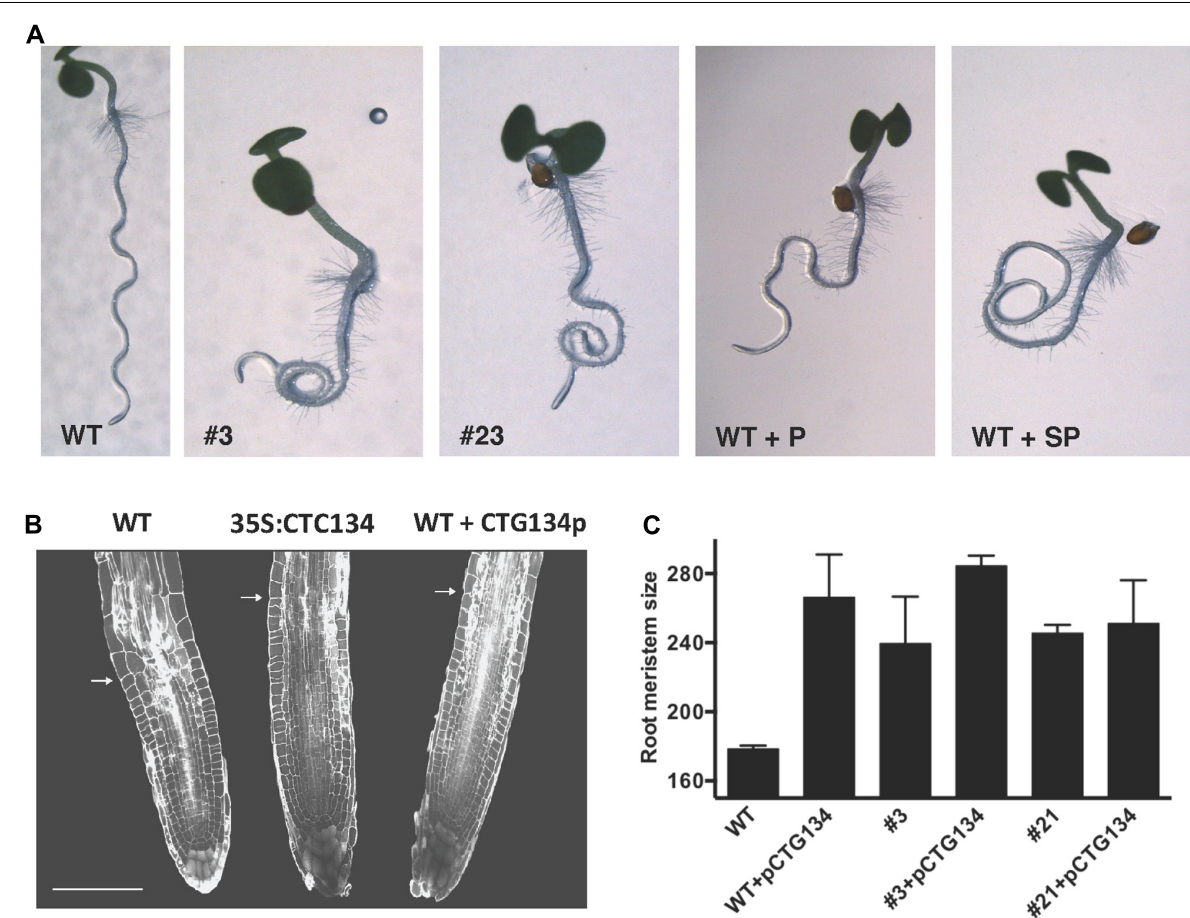

FIGURE 10 | Effects of CTG134 on root gravity perception and on meristem size in Arabidopsis. (A) WT seedlings grown on oblique agar plates showed roots with a regular wavy patter that was altered in CTG134 overexpressing lines (A, \#3 and \#23). Alteration of the wavy pattern was observed also on WT seedlings grown with synthetic CTG134 peptide added to the medium. The effect was stronger if the added peptide was tyrosine-sulfated (WT+SP) compared to the non-sulfated form $(\mathrm{WT}+\mathrm{P})$. (B) Arabidopsis root sections at five DAG, stained with propidium iodide (WT, 35S:CTG134 = overexpressing line, WT + CTG134p = WT grown in the presence of a tyrosine-sulfated synthetic CTG134 peptide). White arrows indicate the transition zone. Scale bar = $100 \mu \mathrm{m}$. (C) Measures of meristem size were statistically (Tukey's multiple comparisons test) larger in comparisons among WT and overexpressing lines (\#3 and \#21), WT grown in the presence of a tyrosine-sulfated synthetic CTG134 peptide (WT+pCTG134) and overexpressing lines grown in the presence of a tyrosine-sulfated synthetic CTG134 peptide (\#3+pCTG134 and \#21+pCTG134). Meristem sizes were not statistically different if WT was excluded. Root meristem was measured using ImageJ software.

respectively. On the contrary, transcription of CTR1, encoding the first downstream signaling component after the ethylene receptor(s) (Kieber et al., 1993) was unaffected (Supplementary Figure 3). About auxin, both TAA1 and YUC3 and 6 genes involved in the indole-3-pyruvic acid branch of the hormone synthesis pathway (Tivendale et al., 2014) were induced in CTG134 overexpressing seedlings, while $A M I 1$, involved in the indole-3-acetamide branch of the pathway, seemed unaffected (Figure 11 and Supplementary Figure 3). Free auxin levels depend not only on hormone synthesis but also on its release from storage compartments and transport. The expression of IAR3, a gene encoding an IAA-Ala hydrolase (Davies et al., 1999), decreased in CTG134 overexpressing plants, while PIN2, encoding an auxin efflux carrier (Müller et al., 1998) was induced (Figure 11).

\section{pCTG134 Induces a Cytosolic $\mathrm{Ca}^{2+}$ Change}

In peach, a gene encoding a $\mathrm{Ca}^{2+}$ sensing protein belonging to the Calcineurin B-like (CBL) family (CTG85) mirrored the expression of CTG134 during fruit ripening, as well as after 1MCP treatment (Tadiello et al., 2016). The expression of CBL1, 2,4 , and 10 encoding genes was therefore tested in 35S:CTG134 roots, showing a general repression, with $C B L 2$ as the most severely down-regulated gene (Figure 11 and Supplementary Figure 3).

Given the effect on CBL gene expression and the potential involvement of $\mathrm{Ca}^{2+}$ in the signaling pathway activated by signaling peptides (Ma et al., 2013), Arabidopsis cell suspension cultures stably expressing the bioluminescent $\mathrm{Ca}^{2+}$ reporter aequorin in the cytosol were challenged with $100 \mu \mathrm{M}$ pCTG134. $\mathrm{Ca}^{2+}$ measurement assays demonstrated the induction of a biphasic cytosolic $\mathrm{Ca}^{2+}$ transient, characterized by a rapid rise, which equally quickly dissipated, followed by a slower $\mathrm{Ca}^{2+}$ increase, peaking at about $0.5 \mu \mathrm{M}$ after $100 \mathrm{~s}$ and falling back to basal levels within $5 \mathrm{~min}$ (Figure 12A). No changes in cytosolic $\mathrm{Ca}^{2+}$ concentration $\left(\left[\mathrm{Ca}^{2+}\right]_{\text {cyt }}\right)$ were detected in response to either plant cell culture medium (Figure 12B) or a non-specific peptide (100 $\mu \mathrm{M}$ T16E S19A2) (Figure 12C), supporting the specificity of the observed $\mathrm{Ca}^{2+}$ response to the sulfated CTG134 peptide.

\section{DISCUSSION}

Peptide hormones participate in both proximal and distal cell-tocell communication processes necessary during growth as well as 

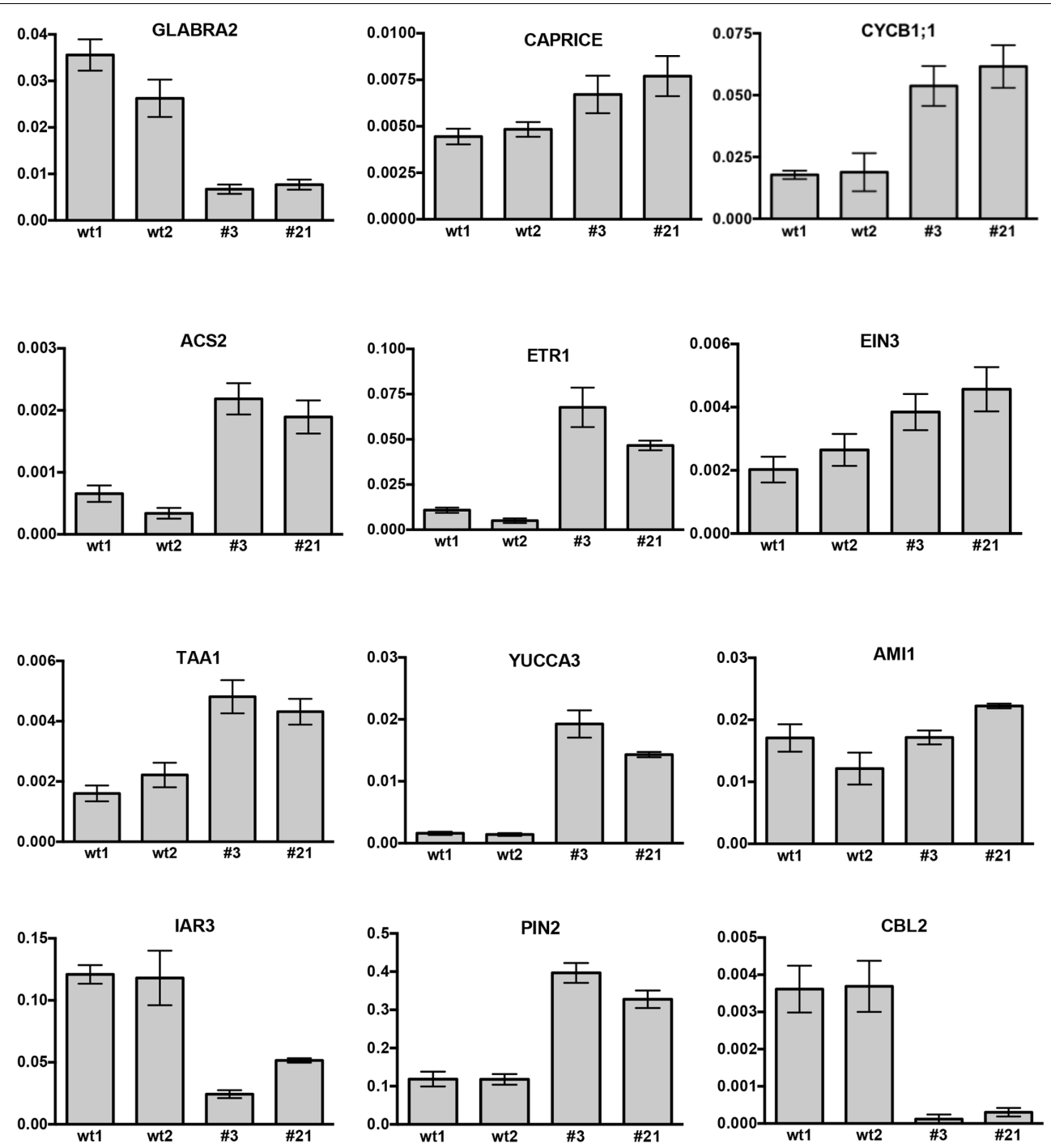

FIGURE 11 | Relative expression profiles of selected genes in roots of Arabidopsis seedlings grown on agar plates for 5 days. wt1 and wt2 are wild type samples collected from two different plates, while \#3 and \#21 are the clone identifiers of the Arabidopsis lines overexpressing the peach CTG134 gene. Values (means of the normalized expression) have been obtained by real-time qRT-PCR analyses. Bars are the standard deviations from the means of three replicates. ACT8 was used as reference gene.

to cope with biotic and abiotic stimuli (reviewed in Matsubayashi, 2014; Tavormina et al., 2015; Wang et al., 2016). Despite the growing interest in peptide hormones, their possible role during fleshy fruit ripening remains almost unexplored (Zhang et al., 2014). In peach fruit, gene expression profiling suggested that CTG134, encoding a peptide belonging to the RGF/GLV family, could be involved in the crosstalk between auxin and ethylene occurring at the onset of fruit ripening (Tadiello et al., 2016).

\section{CTG134 Expression Is Ripening Specific and Affected by Auxin and Ethylene Perception}

Extensive RNA profiling confirmed that CTG134 is expressed almost exclusively at the onset of ripening, during the transition stage from system 1 to 2 (Figure 1), as initially suggested (Tadiello et al., 2016).

Considering the difficulties to perform functional studies in Prunus species due to low efficiency and slowness of their transformation, tobacco and Arabidopsis transgenic lines expressing the GUS reporter gene driven by the CTG134 promoter sequence, were created. The cis-regulatory elements present in the peach CTG134 promoter drive GUS gene expression in cell/tissue types where the crosstalk between auxin and ethylene was described both in tobacco (Figure 2) and Arabidopsis (Figure 3). These comprise both cells undergoing separation processes, like abscission, dehiscence zones, lateral root primordia (Roberts et al., 2002; Kumpf et al., 2013), cambium associated cells (Love et al., 2009; Sanchez et al., 2012) and placenta cells (De Martinis and Mariani, 1999; Pattison et al., 

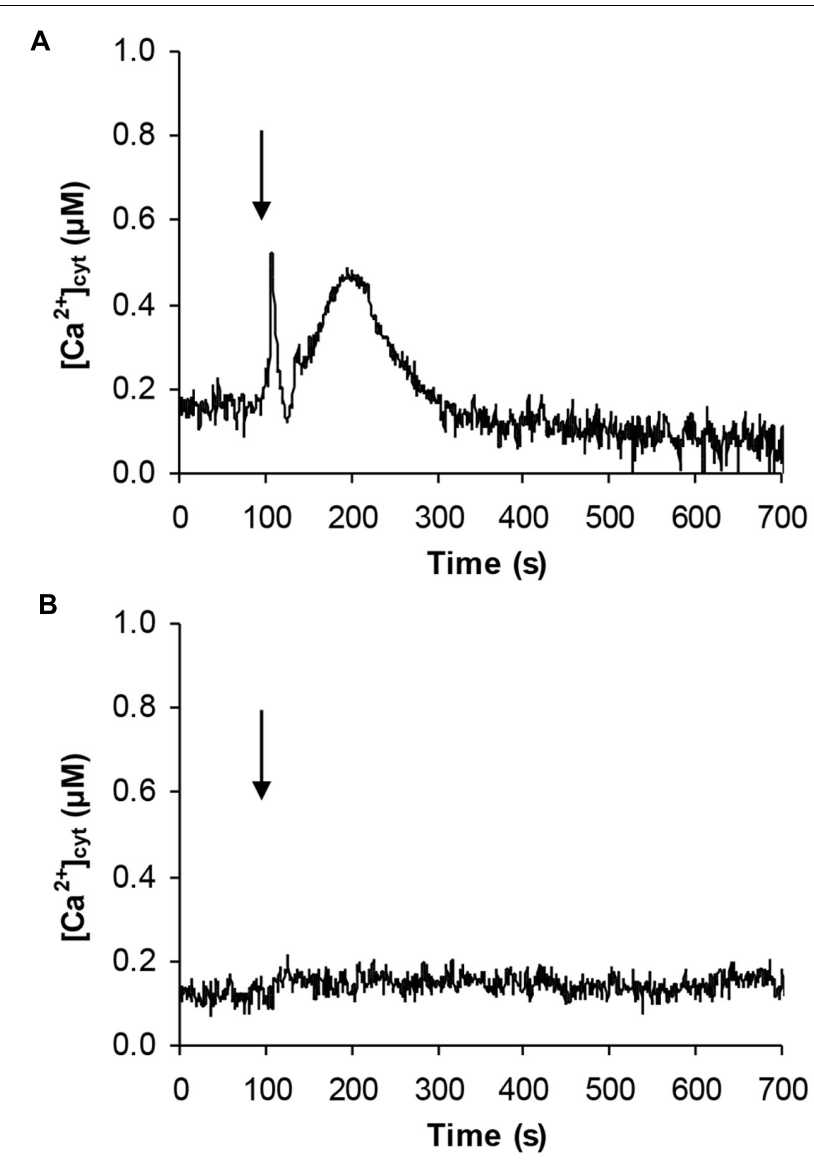

C

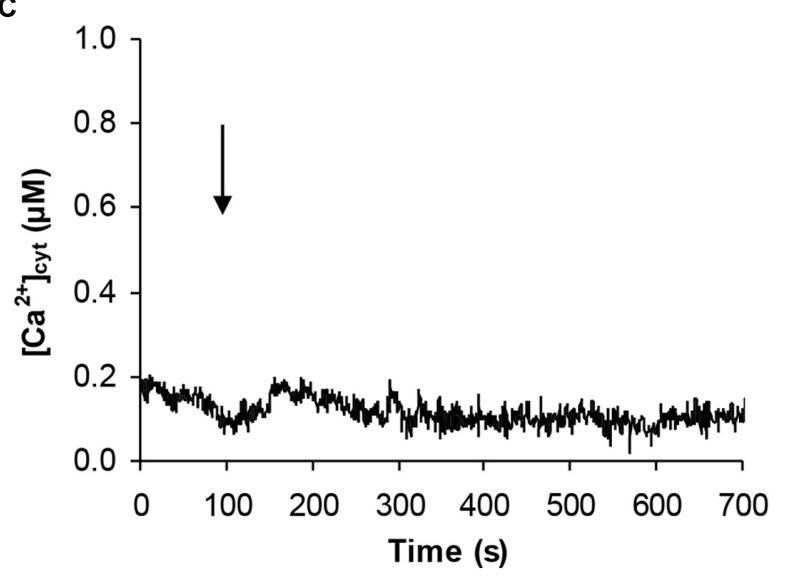

FIGURE 12 | Induction of a transient cytosolic $\mathrm{Ca}^{2+}$ change by the sulphonated peptide CTG134S in Arabidopsis. Cytosolic $\mathrm{Ca}^{2+}$ concentration $\left(\left[\mathrm{Ca}^{2+}\right]_{\mathrm{cyt}}\right)$ was monitored in aequorin-expressing Arabidopsis cell cultures in response to $100 \mu \mathrm{M}$ CTG134S (A). As controls, cells were challenged with plant cell culture medium (B) or with the non-specific peptide T16E S19A2 $(100 \mu \mathrm{M}, \mathbf{C})$. The arrow indicates the time of injection (100 s). $\mathrm{Ca}^{2+}$ traces are representative of three independent experiments which gave very similar results.

2015). The specificity of the GUS staining pattern obtained in heterologous systems was validated by in situ hybridization in peach mesocarp, where CTG134 expression was more abundant in bundle associated cells (Figure 1D). It is noteworthy that also regulatory regions of tomato (Blume and Grierson, 1997), apple (Atkinson et al., 1998) and peach (Moon and Callahan, 2004) ACO genes drove GUS expression more abundantly in bundle than parenchyma cells of tomato pericarp. Besides spatial regulation, also hormone responsiveness within CTG134 regulatory regions supported the role in the crosstalk between auxin and ethylene (Figures 1, 4). Indeed, both on ripening mesocarp and tobacco seedlings, not only IAA had an inductive effect, probably due to the presence of AREs, but also the altered perception of ethylene (due to 1-MCP treatment) stimulated both CTG134 transcription in ripening fruit and GUS accumulation in tobacco seedlings. In ripening peaches 1-MCP induced auxin synthesis (Tadiello et al., 2016), and this might be the reason of the CTG134 induction. 1-MCP treatment might have induced IAA synthesis, and thus GUS expression, also in tobacco seedlings. In roots of Arabidopsis treated with silver [also blocking the perception of ethylene; (Negi et al., 2008)] the exogenous application of 1-MCP might have altered the distribution of IAA, leading to GUS induction.

\section{S:CTG134 Plants Show Phenotypes Related to Auxin and Ethylene Action}

When CTG134 was permanently overexpressed in tobacco and Arabidopsis plants (Figures 5-10), the most striking effect was related to the length and number of root hairs, mimicking the effect of exogenous treatments with auxin or ethylene (Pitts et al., 1998). Adventitious root formation and elongation in tobacco were also affected, as well as capsule size, further supporting the interplay between auxin and ethylene actions. Besides the well-known effect on root hair number and morphology reported for RGF/GLV/CLEL (Whitford et al., 2012; Fernandez et al., 2013) and CLE peptides (Fiers et al., 2005), CTG134 had an impact also on tobacco capsule size. In fact, at maturity, tobacco capsules were $16 \%$ larger than WT on average, similarly to carnation flowers treated with ethylene (Nichols, 1976). Ethylene synthesis is necessary for normal ovule development which impacts flower size (De Martinis and Mariani, 1999). The GUS staining in tobacco placenta and the larger capsules in CTG134 overexpressing plants allow therefore to hypothesize that CTG134 may corroborate auxin inductive and ethylene repressive actions during fruit setting (Martínez et al., 2013; Shinozaki et al., 2015).

\section{Molecular Targets of CTG134}

The Arabidopsis root model was moreover exploited to gain insights into possible regulatory circuits associating CTG134 with auxin and ethylene (Figures 9-11). The wavy root phenotype and the increase in meristem size were observed in both overexpressing and peptide treated seedlings, confirming previous findings (Matsuzaki et al., 2010; Whitford et al., 2012). The observed increase in the meristem size was also supported by the induced expression of $C Y C B 1 ; 1$ (Figure 11), while the down-regulation of GL2 was in agreement 


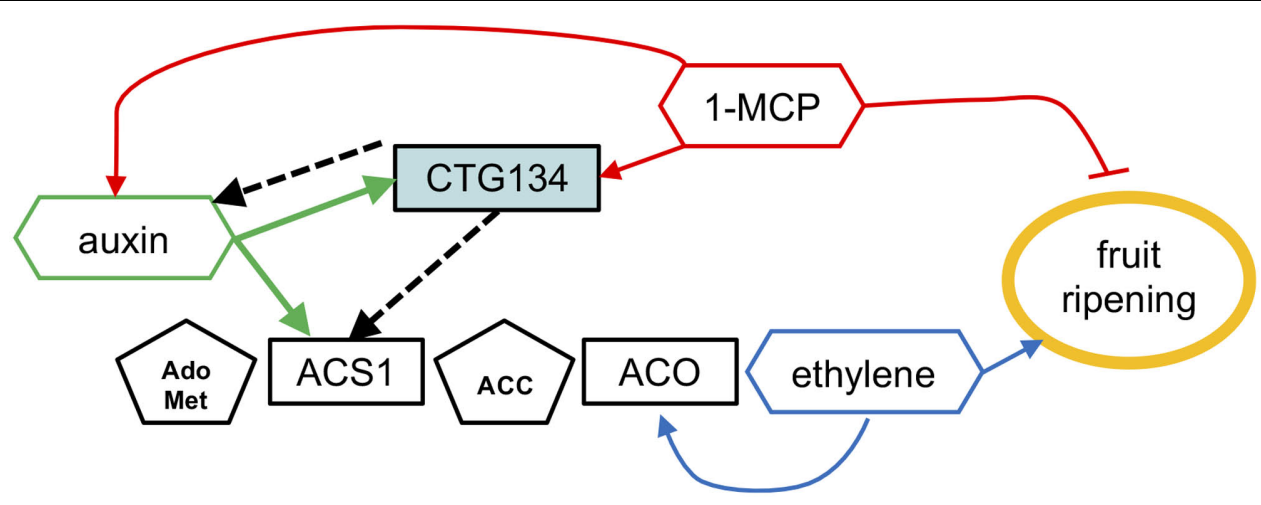

FIGURE 13 | A model positioning CTG134 in the regulatory network controlling peach ripening. Regulatory data collected from the Arabidopsis CTG134 overexpressing clones are represented by dashed lines. Ethylene autocatalytic synthesis and action on fruit ripening is represented in blue, auxin, 1-MCP and CTG134 interactions in green, red and black, respectively. Hormones (or inhibitors) are in hexagons, their precursors in pentagons while genes (gene products) are in rectangles. Filled arrow means induction, while blunted lines repression.

with its repressing role in root hair development (Ishida et al., 2008). More interestingly, genes of both auxin and ethylene synthesis, transport and transduction pathways were upregulated in CTG134 overexpressing roots, assigning to this RGF/GLV peptide a role in the auxin/ethylene crosstalk (Stepanova et al., 2007). Although we did not carry out a detailed analysis on the effects caused by the local application of CTG134 peptide (that in Arabidopsis controlled PIN2 abundance in the root meristem by a post-transcriptional mechanism, thus guiding auxin distribution; Whitford et al., 2012), we showed that the heterologous overexpression of the peach CTG134 peptide could be sensed in the portion of the root where receptors initiate the signaling cascade (Ou et al., 2016; Shinohara et al., 2016; Song et al., 2016). As for Peps signaling in Arabidopsis (Ma et al., 2013), aequorin-based $\mathrm{Ca}^{2+}$ measurement assays (Figure 12) demonstrated the induction by the sulfated peptide CTG134 of a remarkable cytosolic $\mathrm{Ca}^{2+}$ change, suggesting the likely involvement of $\mathrm{Ca}^{2+}$ as intracellular messenger in the transduction pathway activated by this signal peptide. The role of $\mathrm{Ca}^{2+}$ is supported also by the downregulation of several CALCINEURIN B-LIKE PROTEIN (CBL) genes in roots of CTG134 overexpressing seedlings, in agreement with the downregulation of a CBL gene in 1-MCP-treated peaches (Tadiello et al., 2016). Sensing the peptide had also the effect to induce the transcription of key genes of ethylene and auxin biosynthesis pathways and thus, reasonably, the levels of these two hormones which, ultimately, led to the observed phenotypes. While the response in the ethylene pathway is somewhat straightforward investigating the induction of key genes in its synthesis (ACS2), perception (ETR1) and signal transduction (EIN3), the action on the auxin pathway is more intricate. Indeed, while the increased transcription of TAA1, YUC3, and YUC6 sustains the induction of the twostep IPA pathway, the unchanged levels of AMI1 seemed to exclude the conversion of indole-3-acetamide (IAM) to IAA (Enders and Strader, 2015). Moreover, although only IAR3 was tested, the contribution of conjugated forms of IAA (Sanchez Carranza et al., 2016) seemed negligible in Arabidopsis, while the expression of its peach homolog CTG475 was supposed to participate to the free auxin increase measured before the climacteric production of ethylene in peach (Tadiello et al., 2016), thus complementing the role of PpYUC11 (Pan et al., 2015). However, the induced transcription of PIN genes in overexpressing Arabidopsis seedlings (Figure 11) and in climacteric peaches (Tadiello et al., 2016) supported a key role of these peptides in regulating auxin distribution (Whitford et al., 2012).

\section{A Role for CTG134 As Mediator in the Auxin/Ethylene Crosstalk}

The comprehensive expression profiling data carried out in peach (Tadiello et al., 2016) and the knowledge here achieved about CTG134 in tobacco and Arabidopsis provide evidence on the involvement of this RGF/GVL secreted peptide in a regulatory circuit that sustains auxin and ethylene actions. The same circuit, working in both rosids (Arabidopsis) and asterids (tobacco) might have appeared early during evolution of eudicots to participate in the control of root hair development and later it could have been recruited in peach to regulate the switch from system 1 to system 2 ethylene synthesis (Figure 13). Further research will be necessary to clarify the molecular details by which CTG134 acts to either regulate auxin and ethylene synthesis or modify their distribution and perception, or both. The kinase nature of GLVs receptors (Ou et al., 2016; Shinohara et al., 2016; Song et al., 2016) agrees with the measured $\mathrm{Ca}^{2+}$ perturbations.

The unique mechanism that switches ethylene synthesis from system 1 to system 2 in peach probably relies on the use of a single ACS gene for both kinds of syntheses (Tadiello et al., 2016), thus differing from tomato (Barry et al., 2000) and apple (Wang et al., 2009). In these two latter fruits, the expression of LeACS4 and MdACS3 (system 1) is necessary to start LeACS2 and $M d A C S 1$ transcription (system 2), respectively. During peach ripening, expression of other ACS genes is, if present, several orders of magnitude lower than that of ACS1 (Tadiello et al., 2016). The different amount of ethylene released by system 1 and 
system 2 could be achieved by modulating system 1 ACS1 activity, thus leading to system 2 ACS1 increased transcription. ACS1 belongs to type-1 ACS proteins, which are stabilized by phosphorylation mediated by mitogen-activated protein kinases (MAPKs) (Liu and Zhang, 2004). Phosphorylation cascades have been shown to start upon binding of peptide signals (e.g., IDA) with their receptors (e.g., HAE/HSL2) (Cho et al., 2008). Given the transcriptional regulation of CTG134, the nature of pCTG134 and of the Arabidopsis receptors of its homologous RGF/GLV peptides (Ou et al., 2016; Shinohara et al., 2016; Song et al., 2016) and of the ability of pCTG134 to trigger a cytosolic $\mathrm{Ca}^{2+}$ signal, we hypothesized that the transition of ethylene synthesis from system 1 to system 2 in peach could be controlled by ACS1, whose activity might be therefore modulated through the action of pCTG134. The apoplastic nature of these ligands and the possibility to modulate their biological activity by antagonistic forms (Lee et al., 2015) open the possibility for the rational design of novel and environmental friendly agrochemicals with the potential of being used both in the field and during post-harvest to improve fruit storage and fruit quality in a rapidly changing environment.

\section{AUTHOR CONTRIBUTIONS}

Conceptualization: LT. Methodology: NB, DM, LN, FR, and LT. Investigation: NB, LN, SQ, FR, and US. Writing - Original Draft: $\mathrm{NB}$ and LT. Writing - Review and Editing, NB, LN, US, FC,

\section{REFERENCES}

Atkinson, R. G., Bolitho, K. M., Wright, M. A., Iturriagagoitia-Bueno, T., Reid, S. J., and Ross, G. S. (1998). Apple ACC-oxidase and polygalacturonase: ripeningspecific gene expression and promoter analysis in transgenic tomato. Plant Mol. Biol. 38, 449-460. doi: 10.1023/A:1006065926397

Barry, C. S., Llop-Tous, M. I., and Grierson, D. (2000). The regulation of 1aminocyclopropane-1-carboxylic acid synthase gene expression during the transition from system-1 to system-2 ethylene synthesis in tomato. Plant Physiol. 123, 979-986. doi: 10.1104/pp.123.3.979

Blume, B., and Grierson, D. (1997). Expression of ACC oxidase promoter-GUS fusions in tomato and Nicotiana plumbaginifolia regulated by developmental and environmental stimuli. Plant J. 12, 731-746. doi: 10.1046/j.1365-313X. 1997.12040731.x

Bradford, M. M. (1976). A rapid and sensitive method for the quantitation of microgram quantities of protein utilizing the principle of proteindye binding. Anal. Biochem. 72, 248-254. doi: 10.1016/0003-2697(76) 90527-3

Brambilla, V., Battaglia, R., Colombo, M., Masiero, S., Bencivenga, S., Kater, M. M., et al. (2007). Genetic and molecular interactions between BELL1 and MADS box factors support ovule development in Arabidopsis. Plant Cell 19, 2544-2556. doi: 10.1105/tpc.107.051797

Carpino, L. A., Henklein, P., Foxman, B. M., Abdelmoty, I., Costisella, B., Wray, V., et al. (2001). The solid state and solution structure of HAPyU. J. Org. Chem. 66, 5245-5247. doi: 10.1021/jo001616+

Chang, S., Puryear, J., and Cairney, J. (1993). A simple and efficient method for isolating RNA from pine trees. Plant Mol. Biol. Rep. 11, 113-116. doi: 10.1007/ BF02670468

Cho, S. K., Larue, C. T., Chevalier, D., Wang, H., Jinn, T.-L., Zhang, S., et al. (2008). Regulation of floral organ abscission in Arabidopsis thaliana. Proc. Natl. Acad. Sci. U.S.A. 105, 15629-15634. doi: 10.1073/pnas.0805539105 and LT. Funding Acquisition: LT. Resources: DM, OM, and MP. Supervision: LT and DM.

\section{FUNDING}

This work was supported by MIUR (Italian Ministry of Research and University), MiPAFF (Ministero delle Politiche Agricole Alimentari e Forestali-Italy; www.politicheagricole.it) through the project 'DRUPOMICS' (grant DM14999/7303/08) and the University of Padova (grant CPDA072133/07 and CPDA132841/13).

\section{ACKNOWLEDGMENTS}

We thank M.R. Knight (Durham, United Kingdom) and G. Regiroli (AgroFresh Inc., Philadelphia, PA, United States) for kindly providing seeds of aequorin-expressing Arabidopsis plants and SmartFresh ${ }^{\mathrm{TM}}$ (1-MCP), respectively. The authors are also grateful to Alice Tadiello and Maria P. Schiappelli for providing preliminary expression data and support in peptide synthesis.

\section{SUPPLEMENTARY MATERIAL}

The Supplementary Material for this article can be found online at: https://www.frontiersin.org/articles/10.3389/fpls.2017.01711/ full\#supplementary-material

Clough, S. J., and Bent, A. F. (1998). Floral dip: a simplified method for Agrobacterium-mediated transformation of Arabidopsis thaliana. Plant J. Cell Mol. Biol. 16, 735-743. doi: 10.1046/j.1365-313x.1998.00343.x

Davies, R. T., Goetz, D. H., Lasswell, J., Anderson, M. N., and Bartel, B. (1999). IAR3 encodes an auxin conjugate hydrolase from Arabidopsis. Plant Cell 11, 365-376. doi: 10.1105/tpc.11.3.365

De Martinis, D., and Mariani, C. (1999). Silencing gene expression of the ethyleneforming enzyme results in a reversible inhibition of ovule development in transgenic tobacco plants. Plant Cell 11, 1061-1072. doi: 10.1105/tpc.11.6. 1061

Dolan, L. (2001). The role of ethylene in root hair growth in Arabidopsis. J. Plant Nutr. Soil Sci. 164, 141-145. doi: 10.1002/1522-2624(200104)164:2<141::AIDJPLN141<3.0.CO;2-Z

Enders, T. A., and Strader, L. C. (2015). Auxin activity: past, present, and future. Am. J. Bot. 102, 180-196. doi: 10.3732/ajb.1400285

Fernandez, A., Drozdzecki, A., Hoogewijs, K., Nguyen, A., Beeckman, T., Madder, A., et al. (2013). Transcriptional and functional classification of the GOLVEN/ROOT GROWTH FACTOR/CLE-like signaling peptides reveals their role in lateral root and hair formation. Plant Physiol. 161, 954-970. doi: 10.1104/pp.112.206029

Fields, G. B., and Noble, R. L. (1990). Solid phase peptide synthesis utilizing 9fluorenylmethoxycarbonyl amino acids. Int. J. Pept. Protein Res. 35, 161-214. doi: 10.1111/j.1399-3011.1990.tb00939.x

Fiers, M., Golemiec, E., Xu, J., van der Geest, L., Heidstra, R., Stiekema, W., et al. (2005). The 14-amino acid CLV3, CLE19, and CLE40 peptides trigger consumption of the root meristem in Arabidopsis through a CLAVATA2dependent pathway. Plant Cell 17, 2542-2553. doi: 10.1105/tpc.105. 034009

Fisher, D. K., and Guiltinan, M. J. (1995). Rapid, efficient production of homozygous transgenic tobacco plants with Agrobacterium tumefaciens: a seedto-seed protocol. Plant Mol. Biol. Rep. 13, 278-289. doi: 10.1007/BF02670906 
Hellens, R. P., Edwards, E. A., Leyland, N. R., Bean, S., and Mullineaux, P. M. (2000). pGreen: a versatile and flexible binary Ti vector for Agrobacteriummediated plant transformation. Plant Mol. Biol. 42, 819-832. doi: 10.1023/A: 1006496308160

Ishida, T., Kurata, T., Okada, K., and Wada, T. (2008). A genetic regulatory network in the development of trichomes and root hairs. Annu. Rev. Plant Biol. 59, 365-386. doi: 10.1146/annurev.arplant.59.032607.092949

Jefferson, R. A., Kavanagh, T. A., and Bevan, M. W. (1987). GUS fusions: betaglucuronidase as a sensitive and versatile gene fusion marker in higher plants. EMBO J. 6, 3901-3907.

Kieber, J. J., Rothenberg, M., Roman, G., Feldmann, K. A., and Ecker, J. R. (1993). CTR1, a negative regulator of the ethylene response pathway in arabidopsis, encodes a member of the Raf family of protein kinases. Cell 72, 427-441. doi: 10.1016/0092-8674(93)90119-B

Kumpf, R. P., Shi, C.-L., Larrieu, A., Stø, I. M., Butenko, M. A., Péret, B., et al. (2013). Floral organ abscission peptide IDA and its HAE/HSL2 receptors control cell separation during lateral root emergence. Proc. Natl. Acad. Sci. U.S.A. 110, 5235-5240. doi: 10.1073/pnas.1210835110

Lee, J. S., Hnilova, M., Maes, M., Lin, Y.-C. L., Putarjunan, A., Han, S.-K., et al. (2015). Competitive binding of antagonistic peptides fine-tunes stomatal patterning. Nature 522, 439-443. doi: 10.1038/nature14561

Liu, Y., and Zhang, S. (2004). Phosphorylation of 1-aminocyclopropane-1carboxylic acid synthase by MPK6, a stress-responsive mitogen-activated protein kinase, induces ethylene biosynthesis in Arabidopsis. Plant Cell 16, 3386-3399. doi: 10.1105/tpc.104.026609

Looney, N. E., McGlasson, W. B., and Coombe, B. G. (1974). Control of fruit ripening in peach, Prunus persica: action of succinic acid-2, 2dimethylhydrazide and (2-chloroethyl) phosphonic acid. Funct. Plant Biol. 1, 77-86. doi: 10.1071/PP9740077

Love, J., Björklund, S., Vahala, J., Hertzberg, M., Kangasjärvi, J., and Sundberg, B. (2009). Ethylene is an endogenous stimulator of cell division in the cambial meristem of Populus. Proc. Natl. Acad. Sci. U.S.A. 106, 5984-5989. doi: 10.1073/ pnas.0811660106

Luehrsen, K. R., de Wet, J. R., and Walbot, V. (1992). Transient expression analysis in plants using firefly luciferase reporter gene. Methods Enzymol. 216, 397-414. doi: 10.1016/0076-6879(92)16037-K

Ma, Y., Zhao, Y., Walker, R. K., and Berkowitz, G. A. (2013). Molecular steps in the immune signaling pathway evoked by plant elicitor peptides: $\mathrm{Ca}^{2+}$-dependent protein kinases, nitric oxide, and reactive oxygen species are downstream from the early $\mathrm{Ca}^{2+}$ signal. Plant Physiol. 163, 1459-1471. doi: 10.1104/pp.113. 226068

Martínez, C., Manzano, S., Megías, Z., Garrido, D., Picó, B., and Jamilena, M. (2013). Involvement of ethylene biosynthesis and signalling in fruit set and early fruit development in zucchini squash (Cucurbita pepo L.). BMC Plant Biol. 13:139. doi: 10.1186/1471-2229-13-139

Matsubayashi, Y. (2014). Posttranslationally modified small-peptide signals in plants. Annu. Rev. Plant Biol. 65, 385-413. doi: 10.1146/annurev-arplant050312-120122

Matsuzaki, Y., Ogawa-Ohnishi, M., Mori, A., and Matsubayashi, Y. (2010). Secreted peptide signals required for maintenance of root stem cell niche in Arabidopsis. Science 329, 1065-1067. doi: 10.1126/science. 1191132

Miller, A. N., Walsh, C. S., and Cohen, J. D. (1987). Measurement of indole-3-acetic acid in peach fruits (Prunus persica L. Batsch cv Redhaven) during development. Plant Physiol. 84, 491-494. doi: 10.1104/pp.84.2.491

Moon, H., and Callahan, A. M. (2004). Developmental regulation of peach ACC oxidase promoter-GUS fusions in transgenic tomato fruits. J. Exp. Bot. 55, 1519-1528. doi: 10.1093/jxb/erh162

Müller, A., Guan, C., Gälweiler, L., Tänzler, P., Huijser, P., Marchant, A., et al. (1998). AtPIN2 defines a locus of Arabidopsis for root gravitropism control. EMBO J. 17, 6903-6911. doi: 10.1093/emboj/17.23.6903

Murashige, T., and Skoog, F. (1962). A revised medium for rapid growth and bio assays with tobacco tissue cultures. Physiol. Plant. 15, 473-497. doi: 10.1111/j. 1399-3054.1962.tb08052.x

Negi, S., Ivanchenko, M. G., and Muday, G. K. (2008). Ethylene regulates lateral root formation and auxin transport in Arabidopsis thaliana. Plant J. 55, 175-187. doi: 10.1111/j.1365-313X.2008.03495.x
Nichols, R. (1976). Cell enlargement and sugar accumulation in the gynaecium of the glasshouse carnation (Dianthus caryophyllus L.) induced by ethylene. Planta 130, 47-52. doi: 10.1007/BF00390843

Ou, Y., Lu, X., Zi, Q., Xun, Q., Zhang, J., Wu, Y., et al. (2016). RGF1 INSENSITIVE 1 to 5 , a group of LRR receptor-like kinases, are essential for the perception of root meristem growth factor 1 in Arabidopsis thaliana. Cell Res. 26, 686-698. doi: $10.1038 / \mathrm{cr} .2016 .63$

Pan, L., Zeng, W., Niu, L., Lu, Z., Liu, H., Cui, G., et al. (2015). PpYUC11, a strong candidate gene for the stony hard phenotype in peach (Prunus persica L. Batsch), participates in IAA biosynthesis during fruit ripening. J. Exp. Bot. 66, 7031-7044. doi: 10.1093/jxb/erv400

Pattison, R. J., Csukasi, F., Zheng, Y., Fei, Z., van der Knaap, E., and Catalá, C. (2015). Comprehensive tissue-specific transcriptome analysis reveals distinct regulatory programs during early tomato fruit development. Plant Physiol. 168, 1684-1701. doi: 10.1104/pp.15.00287

Pitts, R. J., Cernac, A., and Estelle, M. (1998). Auxin and ethylene promote root hair elongation in Arabidopsis. Plant J. 16, 553-560. doi: 10.1046/j.1365-313x. 1998.00321.x

Roberts, J. A., Elliott, K. A., and Gonzalez-Carranza, Z. H. (2002). Abscission, dehiscence, and other cell separation processes. Annu. Rev. Plant Biol. 53, 131-158. doi: 10.1146/annurev.arplant.53.092701.180236

Sanchez, P., Nehlin, L., and Greb, T. (2012). From thin to thick: major transitions during stem development. Trends Plant Sci. 17, 113-121. doi: 10.1016/j.tplants. 2011.11.004

Sanchez Carranza, A. P., Singh, A., Steinberger, K., Panigrahi, K., Palme, K., Dovzhenko, A., et al. (2016). Hydrolases of the ILR1-like family of Arabidopsis thaliana modulate auxin response by regulating auxin homeostasis in the endoplasmic reticulum. Sci. Rep. 6:24212. doi: 10.1038/srep 24212

Sello, S., Perotto, J., Carraretto, L., Szabò, I., Vothknecht, U. C., and Navazio, L. (2016). Dissecting stimulus-specific $\mathrm{Ca}^{2+}$ signals in amyloplasts and chloroplasts of Arabidopsis thaliana cell suspension cultures. J. Exp. Bot. 67, 3965-3974. doi: 10.1093/jxb/erw038

Shinohara, H., Mori, A., Yasue, N., Sumida, K., and Matsubayashi, Y. (2016). Identification of three LRR-RKs involved in perception of root meristem growth factor in Arabidopsis. Proc. Natl. Acad. Sci. U.S.A. 113, 3897-3902. doi: 10.1073/ pnas. 1522639113

Shinozaki, Y., Hao, S., Kojima, M., Sakakibara, H., Ozeki-Iida, Y., Zheng, Y., et al. (2015). Ethylene suppresses tomato (Solanum lycopersicum) fruit set through modification of gibberellin metabolism. Plant J. 83, 237-251. doi: 10.1111/tpj. 12882

Song, W., Liu, L., Wang, J., Wu, Z., Zhang, H., Tang, J., et al. (2016). Signature motif-guided identification of receptors for peptide hormones essential for root meristem growth. Cell Res. 26, 674-685. doi: 10.1038/cr. 2016.62

Stepanova, A. N., Yun, J., Likhacheva, A. V., and Alonso, J. M. (2007). Multilevel interactions between ethylene and auxin in Arabidopsis roots. Plant Cell 19, 2169-2185. doi: 10.1105/tpc.107.052068

Tadiello, A., Ziosi, V., Negri, A. S., Noferini, M., Fiori, G., Busatto, N., et al. (2016). On the role of ethylene, auxin and a GOLVEN-like peptide hormone in the regulation of peach ripening. BMC Plant Biol. 16:44. doi: 10.1186/s12870-0160730-7

Tatsuki, M., Nakajima, N., Fujii, H., Shimada, T., Nakano, M., Hayashi, K., et al. (2013). Increased levels of IAA are required for system 2 ethylene synthesis causing fruit softening in peach (Prunus persica L. Batsch). J. Exp. Bot. 64, 1049-1059. doi: 10.1093/jxb/ers381

Tavormina, P., De Coninck, B., Nikonorova, N., De Smet, I., and Cammue, B. P. A. (2015). The plant peptidome: an expanding repertoire of structural features and biological functions. Plant Cell 27, 2095-2118. doi: 10.1105/tpc.15. 00440

Tivendale, N. D., Ross, J. J., and Cohen, J. D. (2014). The shifting paradigms of auxin biosynthesis. Trends Plant Sci. 19, 44-51. doi: 10.1016/j.tplants.2013. 09.012

Trainotti, L., Tadiello, A., and Casadoro, G. (2007). The involvement of auxin in the ripening of climacteric fruits comes of age: the hormone plays a role of its own and has an intense interplay with ethylene in ripening peaches. J. Exp. Bot. 58, 3299-3308. doi: 10.1093/jxb/erm 178 
Van de Poel, B., Smet, D., and Van Der Straeten, D. (2015). Ethylene and hormonal cross talk in vegetative growth and development. Plant Physiol. 169, 61-72. doi: $10.1104 /$ pp.15.00724

Vancanneyt, G., Schmidt, R., O’Connor-Sanchez, A., Willmitzer, L., and RochaSosa, M. (1990). Construction of an intron-containing marker gene: splicing of the intron in transgenic plants and its use in monitoring early events in Agrobacterium-mediated plant transformation. Mol. Gen. Genet. 220, 245-250. doi: 10.1007/BF00260489

Verwoerd, T. C., Dekker, B. M., and Hoekema, A. (1989). A small-scale procedure for the rapid isolation of plant RNAs. Nucleic Acids Res. 17, 2362. doi: 10.1093/ nar/17.6.2362

Wang, A., Yamakake, J., Kudo, H., Wakasa, Y., Hatsuyama, Y., Igarashi, M., et al. (2009). Null mutation of the MdACS3 gene, coding for a ripeningspecific 1-aminocyclopropane-1-carboxylate synthase, leads to long shelf life in apple fruit. Plant Physiol. 151, 391-399. doi: 10.1104/pp.109. 135822

Wang, G., Zhang, G., and Wu, M. (2016). CLE peptide signaling and crosstalk with phytohormones and environmental stimuli. Front. Plant Sci. 6:1211. doi: 10.3389/fpls.2015.01211

Watkins, C. B. (2006). The use of 1-methylcyclopropene (1-MCP) on fruits and vegetables. Biotechnol. Adv. 24, 389-409. doi: 10.1016/j.biotechadv.2006. 01.005

Whitford, R., Fernandez, A., Tejos, R., Pérez, A. C., Kleine-Vehn, J., Vanneste, S., et al. (2012). GOLVEN secretory peptides regulate auxin carrier turnover during plant gravitropic responses. Dev. Cell 22, 678-685. doi: 10.1016/j.devcel.2012. 02.002
Zanchin, A., Bonghi, C., Casadoro, G., Ramina, A., and Rascio, N. (1994). Cell enlargement and cell separation during peach fruit development. Int. J. Plant Sci. 155, 49-56. doi: 10.1086/297146

Zhang, S., Huang, L., Yan, A., Liu, Y., Liu, B., Yu, C., et al. (2016). Multiple phytohormones promote root hair elongation by regulating a similar set of genes in the root epidermis in Arabidopsis. J. Exp. Bot. 67, 6363-6372. doi: $10.1093 / \mathrm{jxb} / \mathrm{erw} 400$

Zhang, Y., Yang, S., Song, Y., and Wang, J. (2014). Genome-wide characterization, expression and functional analysis of CLV3/ESR gene family in tomato. BMC Genomics 15:827. doi: 10.1186/1471-2164-15-827

Ziosi, V., Noferini, M., Fiori, G., Tadiello, A., Trainotti, L., Casadoro, G., et al. (2008). A new index based on vis spectroscopy to characterize the progression of ripening in peach fruit. Postharvest Biol. Technol. 49, 319-329. doi: 10.1016/ j.postharvbio.2008.01.017

Conflict of Interest Statement: The authors declare that the research was conducted in the absence of any commercial or financial relationships that could be construed as a potential conflict of interest.

Copyright (C) 2017 Busatto, Salvagnin, Resentini, Quaresimin, Navazio, Marin, Pellegrini, Costa, Mierke and Trainotti. This is an open-access article distributed under the terms of the Creative Commons Attribution License (CC BY). The use, distribution or reproduction in other forums is permitted, provided the original author(s) or licensor are credited and that the original publication in this journal is cited, in accordance with accepted academic practice. No use, distribution or reproduction is permitted which does not comply with these terms. 